\title{
Bacteriophages vB_Sen-TO17 and vB_Sen-E22, Newly Isolated Viruses from Chicken Feces, Specific for Several Salmonella enterica Strains
}

\author{
Katarzyna Kosznik-Kwaśnicka ${ }^{1}{ }^{(D)}$, Łukasz Grabowski ${ }^{1}{ }^{(D}$, Michał Grabski $^{2,3}$, \\ Mateusz Kaszubski ${ }^{2}$, Marcin Górniak ${ }^{4}{ }^{D}$, Agata Jurczak-Kurek ${ }^{4}$, Grzegorz Węgrzyn ${ }^{2}{ }^{(D)}$ and \\ Alicja Węgrzyn ${ }^{1, *}$ \\ 1 Laboratory of Molecular Biology, Institute of Biochemistry and Biophysics, Polish Academy of Sciences, \\ Kładki 24, 80-822 Gdansk, Poland; k.kwasnicka@hotmail.com (K.K.-K.); \\ lukas.grabowski95@gmail.com (Ł.G.) \\ 2 Department of Molecular Biology, University of Gdansk, Wita Stwosza 59, 80-308 Gdansk, Poland; \\ michal.grabski@phdstud.ug.edu.pl (M.G.); mateuszkaszubski5@wp.pl (M.K.); \\ grzegorz.wegrzyn@biol.ug.edu.pl (G.W.) \\ 3 Institute of Oceanology, Polish Academy of Sciences, Powstańców Warszawy 55, 81-712 Sopot, Poland \\ 4 Department of Molecular Evolution, University of Gdansk, Wita Stwosza 59, 80-308 Gdansk, Poland; \\ marcin.gorniak@ug.edu.pl (M.G.); agata.jurczak-kurek@ug.edu.pl (A.J.-K.) \\ * Correspondence: alicja.wegrzyn@biol.ug.edu.pl; Tel.: +48-58-523-6024
}

Received: 28 October 2020; Accepted: 19 November 2020; Published: 21 November 2020

\begin{abstract}
Two newly discovered bacteriophages, isolated from chicken feces and infecting Salmonella enterica strains, are described in this report. These phages have been named vB_Sen-TO17 and vB_Sen-E22, and we present their molecular and functional characterization. Both studied viruses are able to infect several S. enterica strains and develop lytically, but their specific host ranges differ significantly. Electron microscopic analyses of virions have been performed, and full genome sequences were determined and characterized, along with molecular phylogenetic studies. Genomes of vB_Sen-TO17 (ds DNA of 41,658 bp) and vB_Sen-E22 (dsDNA of 108,987 bp) are devoid of homologs of any known or putative gene coding for toxins or any other proteins potentially deleterious for eukaryotic cells. Both phages adsorbed efficiently ( $>95 \%$ adsorbed virions) within 10 min at $42{ }^{\circ} \mathrm{C}$ (resembling chicken body temperature) on cells of most tested host strains. Kinetics of lytic development of vB_Sen-TO17 and vB_Sen-E22, determined in one-step growth experiments, indicated that development is complete within $30-40 \mathrm{~min}$ at $42^{\circ} \mathrm{C}$, whereas burst sizes vary from 9 to 79 progeny phages per cell for vB_Sen-TO17 and from 18 to 64 for vB_Sen-E22, depending on the host strain. Virions of both phages were relatively stable (from several percent to almost $100 \%$ survivability) under various conditions, including acidic and alkaline $\mathrm{pH}$ values (from 3 to 12), temperatures from $-80^{\circ} \mathrm{C}$ to $60^{\circ} \mathrm{C}, 70 \%$ ethanol, chloroform, and $10 \%$ DMSO. These characteristics of vB_Sen-TO17 and vB_Sen-E22 indicate that these phages might be considered in further studies on phage therapy, particularly in attempts to eliminate $S$. enterica from chicken intestine.
\end{abstract}

Keywords: bacteriophages; Salmonella; lytic development; genomic analysis

\section{Introduction}

Among various foodborne pathogenic bacteria, Salmonella enterica is one of the major infection agents responsible for human diseases caused by contamination of poultry-derived products [1]. While this bacterium usually does not induce any disorders in birds, it can be dangerous to humans. Abundance of $S$. enterica in chicken gut may result in contamination of poultry-derived food appearing 
during the production process [2]. There are various serotypes of S. enterica which can cause diseases in humans, and the problem of salmonellosis is global [3]. In many countries, detection of specific serotypes of S. enterica (in most cases Typhimurium and Enteritidis) in poultry is considered as a compulsion to liquidate the whole flock [1].

Eradication of S. enterica can be performed using antibiotics; however, this method has met serious and global problems [4]. Bacterial strains resistant to many antibiotics are already known, which causes real crisis in therapies of infectious diseases [5,6]. Therefore, it is clear that development of novel methods of treatment of diseases caused by bacteria is necessary $[7,8]$. Phage therapy, i.e., the use of bacteriophages to combat bacterial infections, is one of the possible options [9]. Nevertheless, development of this method is not simple and requires specific conditions [9-11]. It is necessary to establish collections of potentially useful phages which can kill bacteria by conducting lytic development. Since phages are usually very specific to their hosts, such collections should be large to give a possibility of finding viruses capable of propagation in a particular bacterial strain isolated from patients or infected animals. Such bacteriophages must not contain genes coding for toxins and other proteins that might cause damage of human or animal cells. Therefore, it is still necessary to isolate previously unknown bacteriophages and to characterize them [9-11].

The proposal of the use of phage therapy to treat Salmonella infections has been published previously in many reports. Those studies led to determination of properties of various Salmonella-specific phages [12-21], effects of application of phages to poultry [22-27], and results of experimental use of phages in therapies of infected animals [28-32]. In addition, economic analyses of potential use of anti-Salmonella phage therapy in poultry have also been published [1,33]. Despite promising results of these studies, it was also indicated that most phages infecting $S$. enterica have a relatively narrow host range, specific to one or a few serovars or strains [12-21,34]. Thus, characterization of newly isolated bacteriophages infecting this bacterium is reasonable. Following this line of studies, in this report we present isolation and characterization (at both molecular and functional levels) of newly discovered bacteriophages specific to several strains of S. enterica.

\section{Results}

\subsection{Isolation of Bacteriophages}

Newly discovered bacteriophages were isolated from homogenates of chicken feces, using S. enterica serovars Typhimurium 13 and Enteritidis 1392 as hosts, according to a method described in Section 4.3. We isolated 25 different phages which formed five different types of plaques: (i) Turbid with diameter $<1 \mathrm{~mm}$, (ii) turbid with diameter $>1 \mathrm{~mm}$, (iii) clear with diameter $<1 \mathrm{~mm}$, (iv) clear with diameter $>1 \mathrm{~mm}$, and (v) clear with diameter $>1 \mathrm{~mm}$ and forming a halo. Two phages were selected for further analysis-the first one isolated using $S$. Typhimurium 13 as a host (bacteriophage named vB_Sen-TO17) and the second one isolated using $S$. Enteritidis 1392 as a host (bacteriophage named vB_Sen-E22).

\subsection{Plaque and Virion Morphologies}

The first steps of characterization of newly isolated bacteriophages consisted in determination of morphologies of plaques formed by them and morphologies of virions. Both tested phages formed clear plaques on lawns of the $S$. Typhimurium 13 host; however, vB_Sen-TO17 produced significantly larger plaques (with additional halo) than vB_Sen-E22 (Figure 1 and Table 1).

Virion morphology was investigated using electron microscopic methods. Both vB_Sen-TO17 and vB_Sen-E22 are caudate bacteriophages. They have been classified to families Siphoviridae and Demerecviridae, respectively, on the basis of morphology of virions and molecular phylogenetic analyses (see Section 2.7). Electron micrographs of virions of both investigated phages are demonstrated in Figure 2, and quantified details of head and tail structures of virions of vB_Sen-TO17 and vB_Sen-E22 are presented in Table 1. 


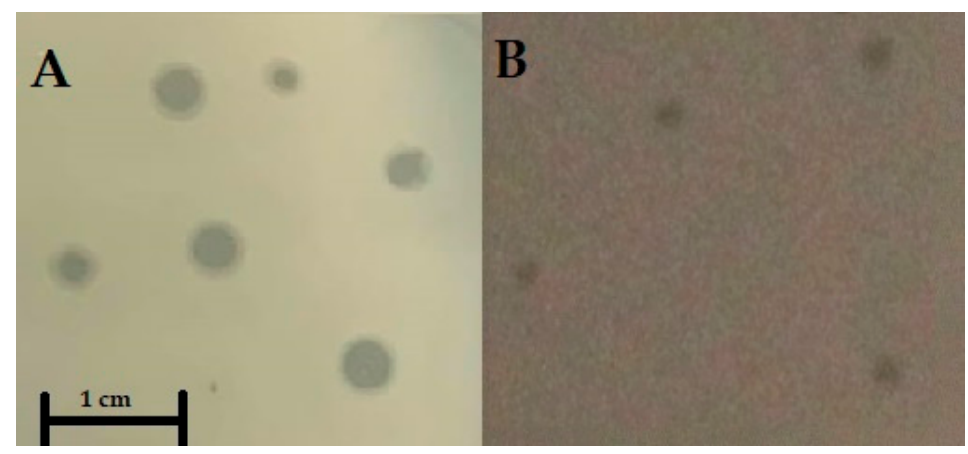

Figure 1. Morphology of plaques of vB_Sen-TO17 (A) and vB_Sen-E22 (B), formed on a lawn of the S. Typhimurium 13 host. A size bar (representing $1 \mathrm{~cm}$ ) is shown at the bottom of panel A.

Table 1. Morphological characteristics of phages vB_Sen-TO17 and vB_Sen-E22. Experiments were performed using $S$. Typhimurium 13 as a host.

\begin{tabular}{ccccc}
\hline \multirow{2}{*}{ Phage Name } & \multirow{2}{*}{ Plaque Morphology } & \multicolumn{3}{c}{ Capsid Morphology } \\
\cline { 3 - 4 } & & Head Diameter & Tail Length & Tail Width \\
\hline \multirow{2}{*}{ vB_Sen-TO17 } & Clear, $\varnothing 2.3-2.5 \mathrm{~mm}$, with & $48 \pm 5 \mathrm{~nm}$ & $121 \pm 8 \mathrm{~nm}$ & $10 \pm 3 \mathrm{~nm}$ \\
vB_Sen-E22 & Clear, $\varnothing 0.8-1.0 \mathrm{~mm}$ & $58 \pm 3 \mathrm{~nm}$ & $88 \pm 6 \mathrm{~nm}$ & $12 \pm 2 \mathrm{~nm}$ \\
\hline
\end{tabular}

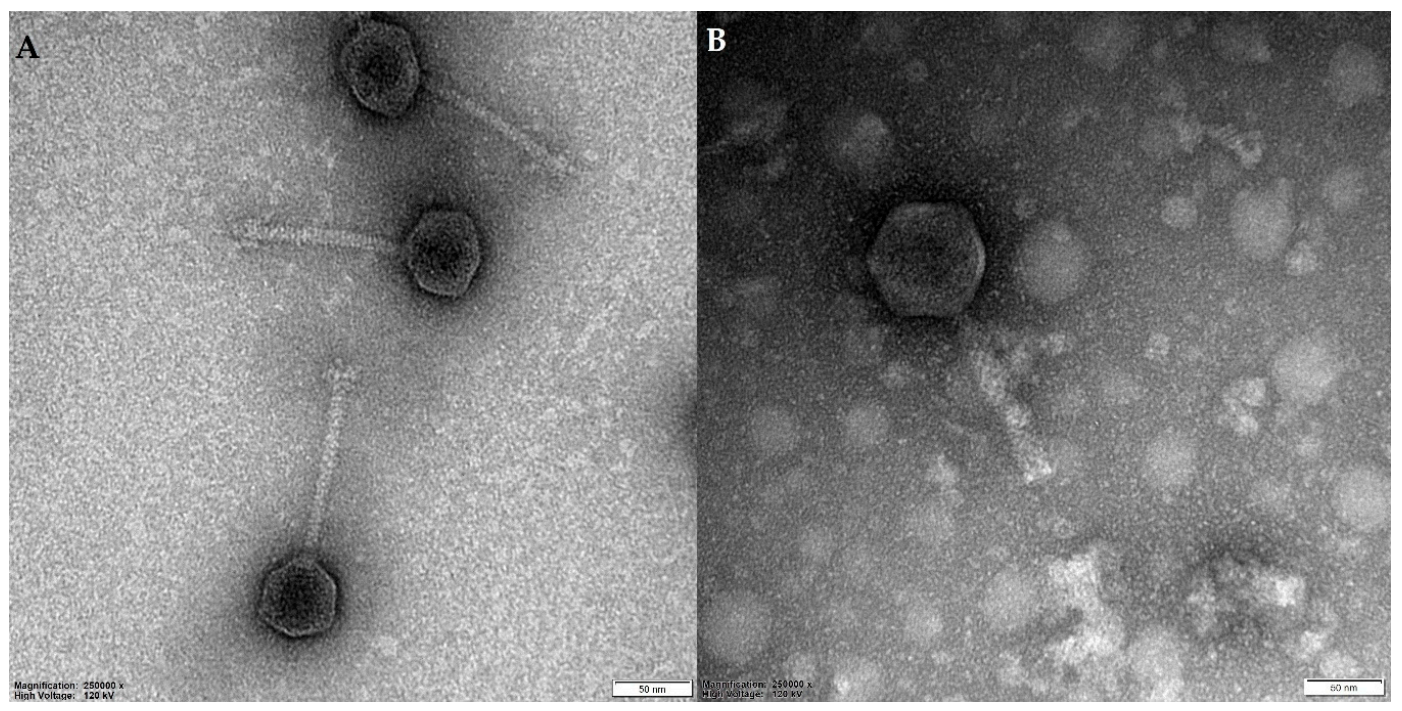

Figure 2. Electron micrographs of virions of vB_Sen-TO17 (A) and vB_Sen-E22 (B). Size bars (representing $50 \mathrm{~nm}$ ) are shown at the bottom of each micrograph.

\subsection{Host Range and Lysogenization Ability}

Host ranges of vB_Sen-TO17 and vB_Sen-E22 were determined using various strains of S. enterica, representing different serovars. In control experiments, bacterial species either closely related to S. enterica, like Escherichia coli, or more distant were used. As expected, these experiments confirmed that vB_Sen-TO17 and vB_Sen-E22 are specific for S. enterica, while revealing different specificities to various strains, with vB_Sen-E22 effectively infecting significantly more strains than vB_Sen-TO17 (Table 2). Nevertheless, S. enterica Gallinarum 74 was infected by vB_Sen-TO17 but not by vB_Sen-E22. These results suggest that both investigated phages might be potentially useful in phage therapy. 
Table 2. Host range of phages vB_Sen-TO17 and vB_Sen-E22.

\begin{tabular}{|c|c|c|}
\hline \multirow[t]{2}{*}{ Bacterial Strain } & \multicolumn{2}{|c|}{ Efficiency of Plating (\%) * } \\
\hline & vB_Sen-TO17 & vB_Sen-E22 \\
\hline Citrobacter freundii & $<0.01$ & $<0.01$ \\
\hline Enterococcus faecalis 230 & $<0.01$ & $<0.01$ \\
\hline Enterococcus faecalis 243 & $<0.01$ & $<0.01$ \\
\hline Escherichia coli $\mathrm{C} 600$ & $<0.01$ & $<0.01$ \\
\hline Escherichia coli MG1655 & $<0.01$ & $<0.01$ \\
\hline Lactobacillus acidophilus $314^{\mathrm{TM}}$ & $<0.01$ & $<0.01$ \\
\hline Lactococcus lactis $49032^{\mathrm{TM}}$ & $<0.01$ & $<0.01$ \\
\hline Proteus vulgaris & $<0.01$ & $<0.01$ \\
\hline Salmonella enterica Agona 1408 & $<0.01$ & $<0.01$ \\
\hline Salmonella enterica Bovismorbificans 300 & $<0.01$ & $<0.01$ \\
\hline Salmonella enterica Choleraesuis 1439 & $<0.01$ & $<0.01$ \\
\hline Salmonella enterica Choleraesuis 34 & $<0.01$ & $68.49 \pm 7.38$ \\
\hline Salmonella enterica Choleraesuis var. Kunzendorf 37 & $<0.01$ & $31.72 \pm 2.55$ \\
\hline Salmonella enterica Derby 20 & $<0.01$ & $<0.01$ \\
\hline Salmonella enterica Dublin 65 & $<0.01$ & $85.94 \pm 6.12$ \\
\hline Salmonella enterica Enteritidis 1392 & $<0.01$ & $100.00 \pm 3.16$ \\
\hline Salmonella enterica Enteritidis 64 & $39.27 \pm 4.87$ & $65.66 \pm 5.18$ \\
\hline Salmonella enterica Gallinarum 74 & $86.72 \pm 4.55$ & $<0.01$ \\
\hline Salmonella enterica Hadar 1748 & $<0.01$ & $<0.01$ \\
\hline Salmonella enterica Heidelberg 16 & $<0.01$ & $91.83 \pm 6.82$ \\
\hline Salmonella enterica Infantis 155 & $<0.01$ & $<0.01$ \\
\hline Salmonella enterica Kentucky 1368 & $<0.01$ & $<0.01$ \\
\hline Salmonella enterica Newport 50 & $<0.01$ & $18.25 \pm 6.51$ \\
\hline Salmonella enterica Newport 51 & $<0.01$ & $<0.01$ \\
\hline Salmonella enterica Saintpaul 435 & $<0.01$ & $<0.01$ \\
\hline Salmonella enterica Senftenberg 87 & $<0.01$ & $56.68 \pm 4.39$ \\
\hline Salmonella enterica Stanley 15 & $<0.01$ & $8.48 \pm 1.32$ \\
\hline Salmonella enterica Thompson 39 & $<0.01$ & $<0.01$ \\
\hline Salmonella enterica Typhimurium 12 & $100.00 \pm 3.22$ & $97.88 \pm 4.13$ \\
\hline Salmonella enterica Typhimurium 13 & $100.00 \pm 2.18$ & $100.00 \pm 6.43$ \\
\hline Salmonella enterica Virchow 41 & $<0.01$ & $85.42 \pm 2.77$ \\
\hline Staphylococcus aureus $6538^{\mathrm{TM}}$ & $<0.01$ & $<0.01$ \\
\hline
\end{tabular}

* Efficiency of plating was calculated on the basis of three independent experiments, and mean values \pm SD are shown. Results obtained with $S$. Typhimurium 13 were considered as $100 \%$, and other values reflect these results.

To test the ability of vB_Sen-TO17 and vB_Sen-E22 to lysogenize host cells, we performed efficiency of lysogenization assessment as described in Section 4.7. However, none of the tested phages were able to form prophages in 10 tested host strains, S. Agona 1408, S. Dublin 65, S. Enteritidis 64, S. Enteritidis 1392, S. Heidelberg 16, S. Infantis 165, S. Newport 50, S. Typhimurium 12, S. Typhimurium 13, and $S$. Virchow 41 (data not shown as no positive results of the test were observed).

\subsection{Sensitivity of Bacteriophages to Various Conditions}

To test if vB_Sen-TO17 and vB_Sen-E22 are sensitive to different environmental conditions, we tested the survival of virions under various $\mathrm{pH}$ (focusing mostly on low $\mathrm{pH}$ conditions, which resemble those occurring in a stomach), the presence of various solvents, and the various temperatures of storage and lytic development.

As indicated in Table 3, while vB_Sen-TO17 and vB_Sen-E22 were completely inactivated at pH 2 or lower, significant fractions of viruses could survive in low $\mathrm{pH}$ conditions of 2.5 (about 4-8\%) or 3.0 (about 55-67\%). Moreover, these viruses could also survive in high $\mathrm{pH}$ conditions (about $72-85 \%$ at $\mathrm{pH} 10$, and about $31-38 \%$ at $\mathrm{pH} 12$ ). These phages were also relatively resistant to ethanol, chloroform, and DMSO, but not to acetone (Table 4). Large fractions (over 55\% of virions) of vB_Sen-TO17 and vB_Sen-E22 could survive at temperatures between $-80^{\circ} \mathrm{C}$ and $60^{\circ} \mathrm{C}$, but not at $95^{\circ} \mathrm{C}$ (Table 5). Optimal 
temperatures for lytic development of both phages were between $37^{\circ} \mathrm{C}$ and $42{ }^{\circ} \mathrm{C}$, while vB_Sen-E22 produced its progeny efficiently also at as low a temperature as $20^{\circ} \mathrm{C}$ (Table 6). All these results indicate that vB_Sen-TO17 and vB_Sen-E22 are relatively resistant to various environmental conditions, suggesting their potential practical usefulness.

Table 3. Susceptibility of phages vB_Sen-TO17 and vB_Sen-E22 to different $\mathrm{pH}$.

\begin{tabular}{cccccccccc}
\hline \multirow{2}{*}{$\begin{array}{c}\text { Phage } \\
\text { Name }\end{array}$} & \multicolumn{7}{c}{ Phage Survivability in Studied Conditions (Relative Phage Titer in \%) } \\
\cline { 2 - 9 } & $\mathbf{p H ~ 1 . 8}$ & $\mathbf{p H ~ 2 . 0}$ & $\mathbf{p H ~ 2 . 2}$ & $\mathbf{p H ~ 2 . 5}$ & $\mathbf{p H ~ 2 . 8}$ & $\mathbf{p H ~ 3 . 0}$ & $\mathbf{p H ~ 7 . 0 *}$ & $\mathbf{p H ~ 1 0 . 0}$ & $\mathbf{p H ~ 1 2 . 0}$ \\
\hline vB_Sen-TO17 & $<0.01$ & $<0.01$ & $11.11 \pm 2.87$ & $7.78 \pm 2.21$ & $18.89 \pm 3.46$ & $66.67 \pm 7.15$ & 100 & $85.41 \pm 5.66$ & $38.75 \pm 3.89$ \\
vB_Sen-E22 & $<0.01$ & $<0.01$ & $<0.01$ & $3.89 \pm 0.95$ & $33.33 \pm 6.17$ & $55.56 \pm 8.55$ & 100 & $72.43 \pm 9.22$ & $31.55 \pm 4.72$ \\
\hline
\end{tabular}

Values obtained at pH 7.0 (marked as *) were assessed as 100\% and other values reflect these controls.

Table 4. Survivability of phages vB_Sen-TO17 and vB_Sen-E22 at different solvents, media, and buffers.

\begin{tabular}{|c|c|c|c|c|c|c|c|}
\hline \multirow[b]{2}{*}{ Phage Name } & \multicolumn{7}{|c|}{ Phage Survivability in Studied Conditions (Relative Phage Titer in \%) } \\
\hline & $\begin{array}{c}70 \% \\
\text { Ethanol }\end{array}$ & Chloroform & $\begin{array}{c}90 \% \\
\text { Acetone }\end{array}$ & $10 \%$ DMSO & DMEM & $10 \%$ SDS & $\begin{array}{c}0.89 \% \\
\mathrm{NaCl}^{*}\end{array}$ \\
\hline vB_Sen-TO17 & $42.63 \pm 4.22$ & $83.33 \pm 5.37$ & $0.88 \pm 0.07$ & $66.42 \pm 7.15$ & $100 \pm 3.16$ & $34.62 \pm 7.16$ & 100 \\
\hline vB_Sen-E22 & $8.75 \pm 1.27$ & $79.81 \pm 6.42$ & $0.23 \pm 0.04$ & $76.63 \pm 6.85$ & $100 \pm 4.28$ & $27.81 \pm 4.21$ & 100 \\
\hline
\end{tabular}

Values obtained for $0.89 \% \mathrm{NaCl}$ (marked as *) were assessed as $100 \%$ and other values reflect these controls.

Table 5. Survivability of phages vB_Sen-TO17 and vB_Sen-E22 at different temperatures.

\begin{tabular}{|c|c|c|c|c|c|c|c|c|}
\hline \multirow[b]{2}{*}{ Phage Name } & \multicolumn{8}{|c|}{ Phage Survivability at Different Temperatures (Relative Phage Titer in \%) } \\
\hline & $\begin{array}{c}-80^{\circ} \mathrm{C} \\
(24 h)\end{array}$ & $\begin{array}{c}-20^{\circ} \mathrm{C} \\
(24 \mathrm{~h})\end{array}$ & $4^{\circ} \mathrm{C}(24 \mathrm{~h})$ & $25^{\circ} \mathrm{C}(24 \mathrm{~h})$ & $\begin{array}{c}37^{\circ} \mathrm{C}^{*} \\
\text { (1h) }\end{array}$ & $42{ }^{\circ} \mathrm{C}(1 \mathrm{~h})$ & $60{ }^{\circ} \mathrm{C}(1 \mathrm{~h})$ & $\begin{array}{c}95^{\circ} \mathrm{C} \\
(5 \mathrm{~min})\end{array}$ \\
\hline vB_Sen-E22 & $62.46 \pm 4.8$ & $55.56 \pm 6.54$ & $100.00 \pm 2.81$ & $100.00 \pm 5.18$ & 100.00 & $100.00 \pm 2.75$ & $88.88 \pm 3.16$ & $<0.01$ \\
\hline
\end{tabular}

Values obtained at $37{ }^{\circ} \mathrm{C}$ (marked as ${ }^{*}$ ) were assessed as $100 \%$ and other values reflect these controls.

Table 6. Efficacy of phage plating of phages vB_Sen-TO17 and vB_Sen-E22 at different temperatures. Control temperature is marked with an asterisk.

\begin{tabular}{ccccc}
\hline \multirow{2}{*}{ Phage Name } & \multicolumn{4}{c}{ Phage Propagation at Different Temperatures (Relative Phage Titer in \%) } \\
\cline { 2 - 5 } & $\mathbf{2 0}{ }^{\circ} \mathbf{C}$ & $\mathbf{2 5}{ }^{\circ} \mathbf{C}$ & $\mathbf{3 7}{ }^{\circ} \mathbf{C}$ & $\mathbf{4 2}{ }^{\circ} \mathbf{C}$ \\
\hline vB_Sen-TO17 & $77.58 \pm 2.66$ & $83.78 \pm 4.83$ & 100.00 & $100.00 \pm 6.21$ \\
vB_Sen-E22 & $100.00 \pm 3.81$ & $98.22 \pm 4.77$ & 100.00 & $100.00 \pm 3.22$ \\
\hline
\end{tabular}

Values obtained at $37{ }^{\circ} \mathrm{C}$ (marked as ${ }^{*}$ ) were assessed as $100 \%$ and other values reflect these controls.

\subsection{Adsorption Efficiency and Kinatics of Lytic Development}

We found that phages vB_Sen-TO17 and vB_Sen-E22 adsorbed efficiently on cells of various S. enterica strains, with above $95 \%$ efficiency within $10 \mathrm{~min}$; the exception was the $S$. Enteritidis 64 host on which the adsorption efficiency was about $80 \%$ within $10 \mathrm{~min}$ (Figure 3). Therefore, this strain appears to be somewhat resistant to its recognition by virions during the first stages of development of phages vB_Sen-TO17 and vB_Sen-E22.

Kinetics of phage development have been investigated in one-step growth experiments. As both phages were isolated from chicken feces and were propagated on S. enterica, these experiments were performed at $42{ }^{\circ} \mathrm{C}$ to resemble conditions occurring in chicken intestine. While efficiency of lytic development was different in various host strains, the eclipse period was between 10 and $20 \mathrm{~min}$, and the development was complete within 30-40 min (Figure 4). Burst sizes of Sen-TO17 and vB_Sen-E22 varied between different host strains, ranging from 9 to 79 progeny phages per cell for vB_Sen-TO17 and from 18 to 64 for vB_Sen-E22 (Table 7). These results indicate that lytic development of both vB_Sen-TO17 and vB_Sen-E22 is effective in various $S$. enterica host strains at $42{ }^{\circ} \mathrm{C}$. 
A

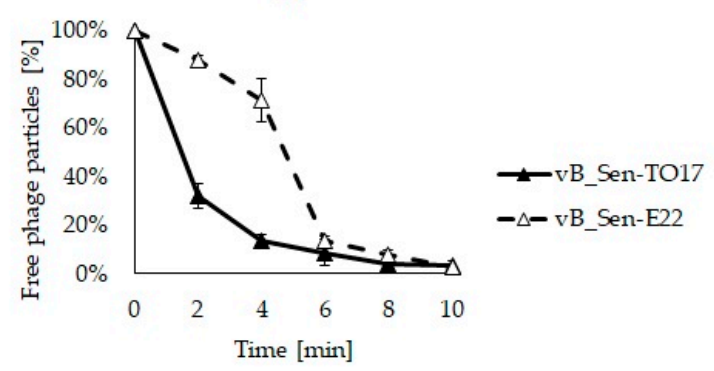

B

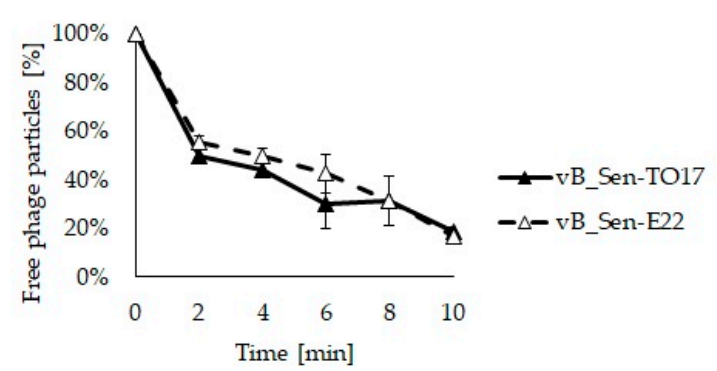

S. Typhimurium 13

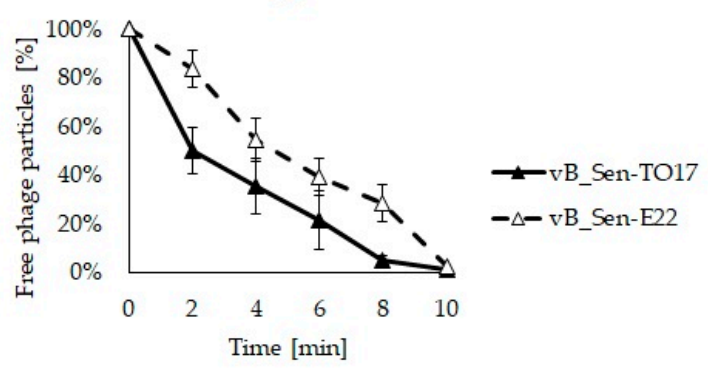

S. Enteritidis 1392

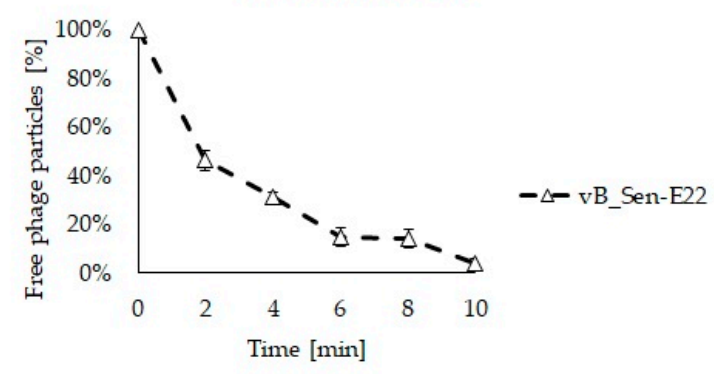

Figure 3. Adsorption rates of phages vB_Sen-TO17 (closed triangles) and vB_Sen-E22 (open triangles) on $S$. Typhimurium (A) and $S$. Enteritidis (B) at $42{ }^{\circ} \mathrm{C}$. Number of free phage particles at time 0 was used as reference value $(100 \%)$. Mean values from three independent experiments are shown, with error bars representing SD. Note that $S$. Enteritidis 1392 is resistant to vB_Sen-TO17 (Table 2); thus, experiments with this strain were performed only for vB_Sen-E22.
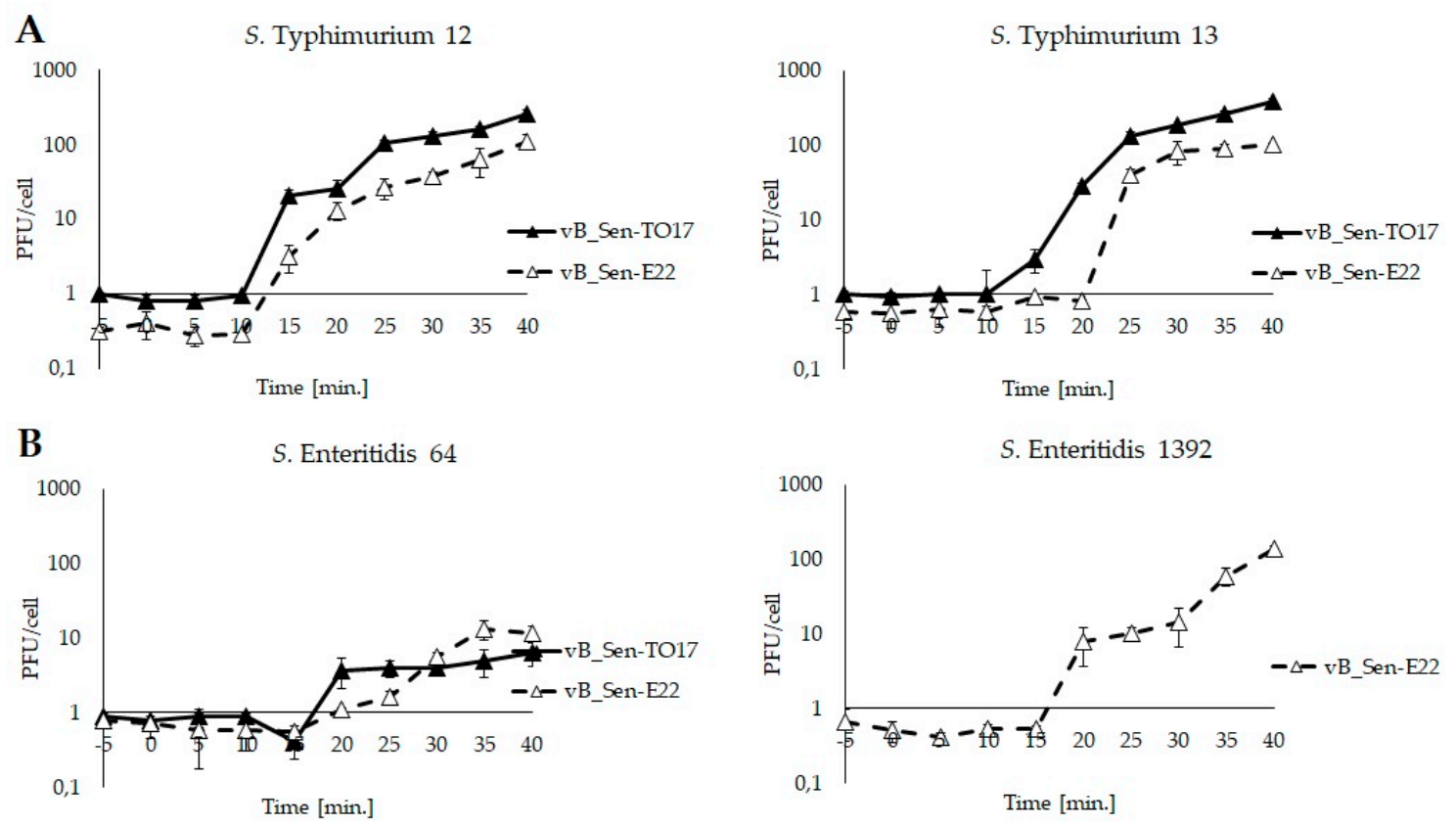

Figure 4. One-step growth experiments with phages vB_Sen-TO17(closed triangles) and vB_Sen-E22 (open triangles) on $S$. Typhimurium (A) and S. Enteritidis (B) at $42{ }^{\circ} \mathrm{C}$; m.o.i. $=0.01$. Mean values from three independent experiments are shown, with error bars representing SD. Note that $S$. Enteritidis 1392 is resistant to $\mathrm{vB} \_$Sen-TO17 (Table 2); thus, experiments with this strain were performed only for vB_Sen-E22. 
Table 7. Burst size of phages vB_Sen-TO17 and vB_Sen-E22 on different S. enterica strains at $42{ }^{\circ} \mathrm{C}$. The burst size was calculated from samples untreated with chloroform during the one-step growth experiment. Mean values from three independent experiments with SD are presented.

\begin{tabular}{cccc}
\hline \multirow{2}{*}{ Phage Name } & \multicolumn{2}{c}{ Salmonella enterica Strain } & \multirow{2}{*}{ Burst Size (PFU/cell) } \\
\cline { 2 - 3 } & Serotype & No. & \\
\hline \multirow{2}{*}{ vB_Sen-TO17 } & Typhimurium & 12 & $58.88 \pm 4.71$ \\
& & 13 & $79.17 \pm 3.77$ \\
& Enteritidis & 64 & $9.27 \pm 2.57$ \\
& & 1392 & - \\
vB_Sen-E22 & Typhimurium & 12 & $55.48 \pm 4.82$ \\
& & 13 & $64.83 \pm 6.36$ \\
& \multirow{2}{*}{ Enteritidis } & 64 & $18.43 \pm 2.15$ \\
& & 1392 & $57.74 \pm 8.47$ \\
\hline
\end{tabular}

\subsection{Analysis of Phage Genomes}

DNA was isolated from purified virions of vB_Sen-TO17 and vB_Sen-E22 and subjected to sequencing, as described in Section 4.14. Annotations of vB_Sen-TO17 and vB_Sen-E22 genomes are presented in Tables S1 and S2, respectively.

The genome of phage vB_Sen-TO17 (whole sequence deposited in GenBank; accession no. MT012729) consists of 41,658 bps, arranged in a linear topology with an overall GC content of $50.78 \%$ (Figure 5). We identified open reading frames (ORFs) putatively coding for 75 proteins, of which 27 were reported previously. The remaining 48 ORFs are described as hypothetical.
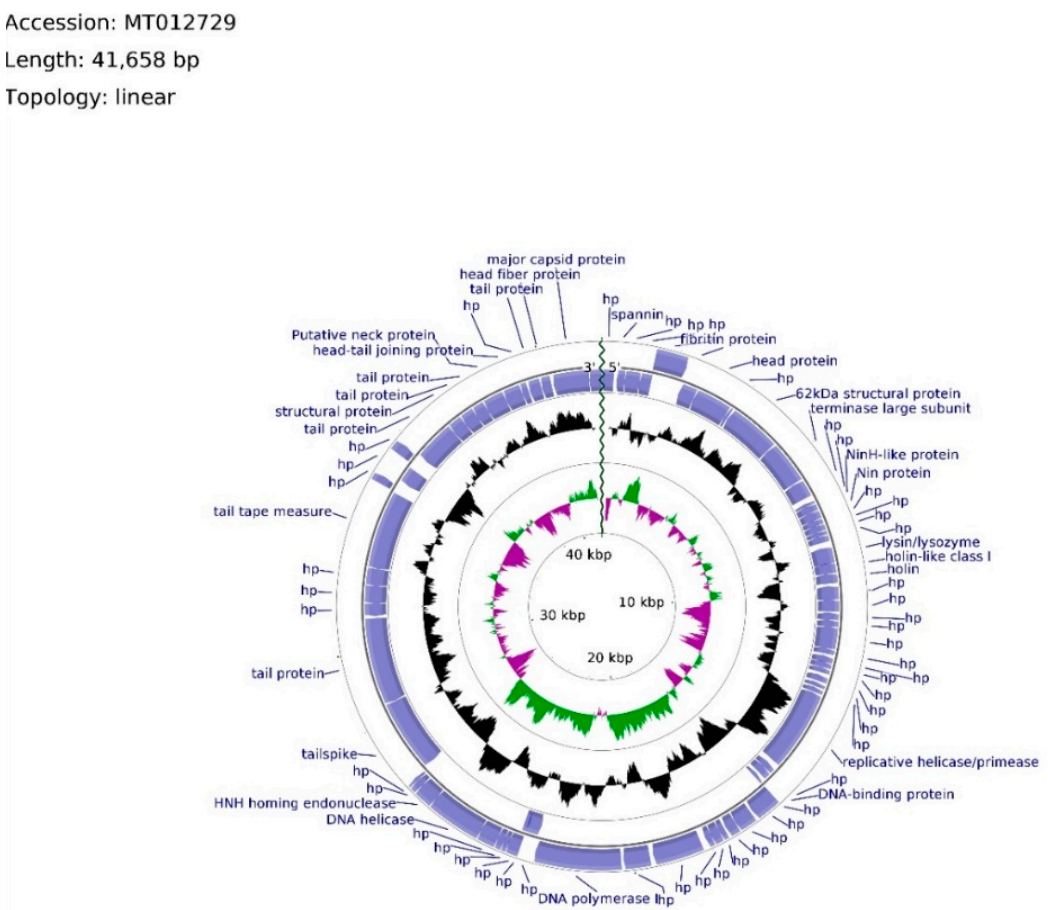

Figure 5. A schematic linear map of phage vB_Sen-TO17 genome (ends of the genome are indicated by the wavy line). The inner rings show genome location, GC skew + (green) and - (purple) and GC content (black). Two the most external rings show identified open reading frames (blue arrows) and results of genome annotation process.

Twenty ORFs are spread out on the leading strand, whereas the majority (55) of ORFs are located on the complementary strand. ATG codon predominates among start codons (70 cases), whereas GTG and TTG occur 3 and 2 times, respectively. ORFs initiating with GTG and TTG codons, with the 
exception of vB_SenTO17_45 (696 bp), have sequence spans $\leq 144 \mathrm{bp}$, where the average length of sequence in the vB_Sen-TO17 genome is $535 \mathrm{bp}$. ATG codon is utilized in every ORF with an assigned function. The frequency of observed stop codons is set out as follows: TAA-40, TGA-28, TAG-7. ORFs were divided into four functional groups due to the assigned functions of their putative products: Morphogenesis (15), DNA replication (4), lysis (3), and DNA packing (2). The total number of ORFs in functional groups was excessive due to the domain determination of hypothetical proteins. In consequence, putatively protein-encoding vB_SenTO17_52, bearing the $\mathrm{HNH}$ endonuclease domain sequence, was classified within the DNA replication functional group, joined with vB_SenTO17_34, vB_SenTO17_36, vB_SenTO17_46, and vB_SenTO17_53, encoding helicase/primase, DNA-binding protein, DNA polymerase I, and DNA helicase (which start codon overlaps vB_SenTO17_52 stop codon), respectively. DNA replication genes are spread within the $12,966-25,568$ bps span. The majority of ORF coding proteins putatively engaged in morphogenesis are located downstream, within the 26,354-41,287 bps region, with the exception of genes encoding fibritin (vB_SenTO17_06), putative head protein (vB_SenTO17_07), and $62 \mathrm{kDa}$ structural protein (vB_SenTO17_09), located at the 2282-5401 bps region. Numerous possible transcription promoters were registered on the complementary strand in the morphogenesis-related region, in relation to the whole genome. The morphogenesis group consists mostly of genes coding for proteins involved in tail assembly (vB_SenTO17_07, vB_SenTO17_57, vB_SenTO17_58, vB_SenTO17_62, vB_SenTO17_66, vB_SenTO17_68, vB_SenTO17_69, vB_SenTO17_73), head (vB_SenTO17_74, vB_SenTO17_75), head-tail joining proteins (vB_SenTO17_70, vB_SenTO17_71), and structural proteins (vB_SenTO17_09, vB_SenTO17_67). Coding DNA Sequences (CDSs) corresponding to lysis proteins are located upstream of the DNA replication span, and occupy positions at 8694-9739 bps. They include ORFs for lysin/lysozyme (vB_SenTO17_19), putative holin-like class I (vB_SenTO17_20), and putative holin (vB_SenTO17_21). Nevertheless, based on nucleotide sequence analysis using the PHACTS algorithm, phage lifestyle was non-confidently classified as temperate. DNA packing CDSs are located within the 5418-6641 bps region, and the 25,565-26,062 bps span consists of genes putatively encoding the terminase large subunit (vB_SenTO17_10) and the HNH homing endonuclease (vB_SenTO17_54). Li's method analysis suggested that phage vB_Sen-TO17 genome is packaged according to the PAC system. Following ORFs: vB_SenTO17_54,vB_SenTO17_53, and vB_SenTO17_46 are the only sequences located on the leading strand which may code for proteins with the reported function.

The genome of phage vB_Sen-E22 (whole sequence deposited in GenBank; accession no. MT311645) consists of $108,987 \mathrm{bp}$, with overall GC content of $39.21 \%$ and linear topology (Figure 6). Determination of ORFs distinguished 158 putative protein-coding genes where 114 were located on the leading strand and 44 were located on the complementary strand. The frequency of start codons is set out as follows: ATG-147, GTG-8, TTG-3. Among termination codons, nucleotide triplet frequencies were set as follows: TAA-124, TGA-25, TAG-8. The functions of $67 \mathrm{ORFs}$ were assigned, whereas 91 remain hypothetical. ORFs with assigned functions were divided into four functional groups: Morphogenesis (22), DNA packing (10), DNA replication (7), and lysis (2). Morphogenesis CDSs are concentrated inside the region of 46,010-74,545 bps, with nine sequences interspersed throughout the vB_Sen-E22 genome, mainly coding for tail-related proteins with the exception of head assembly proteins $v B \_S e n E 22 \_68$ and $v B \_S e n E 22 \_131$. CDSs engaged in tail protein assembly dominate this genome region (11 CDSs), whereas two head-related CDSs, coding for portal protein (vB_SenE22_100) and major head protein precursor (vB_SenE22_103), are also present there. Phage head putative genes are located within the 50,510-54,248 bps span which is intersected with the tail fibers protein putative gene (vB_SenE22_101) and the sequence putatively encoding prohead protease (vB_SenE22_102). DNA packing genes are spread across the vB_Sen-E22 genome, and they include genes encoding putative nucleases: Endonucleases (vB_SenE22_99, vB_SenE22_120, vB_SenE22_123, vB_SenE22_153), exonucleases (vB_SenE22_12, vB_SenE22_112), and ribonuclease H (vB_SenE22_158). 


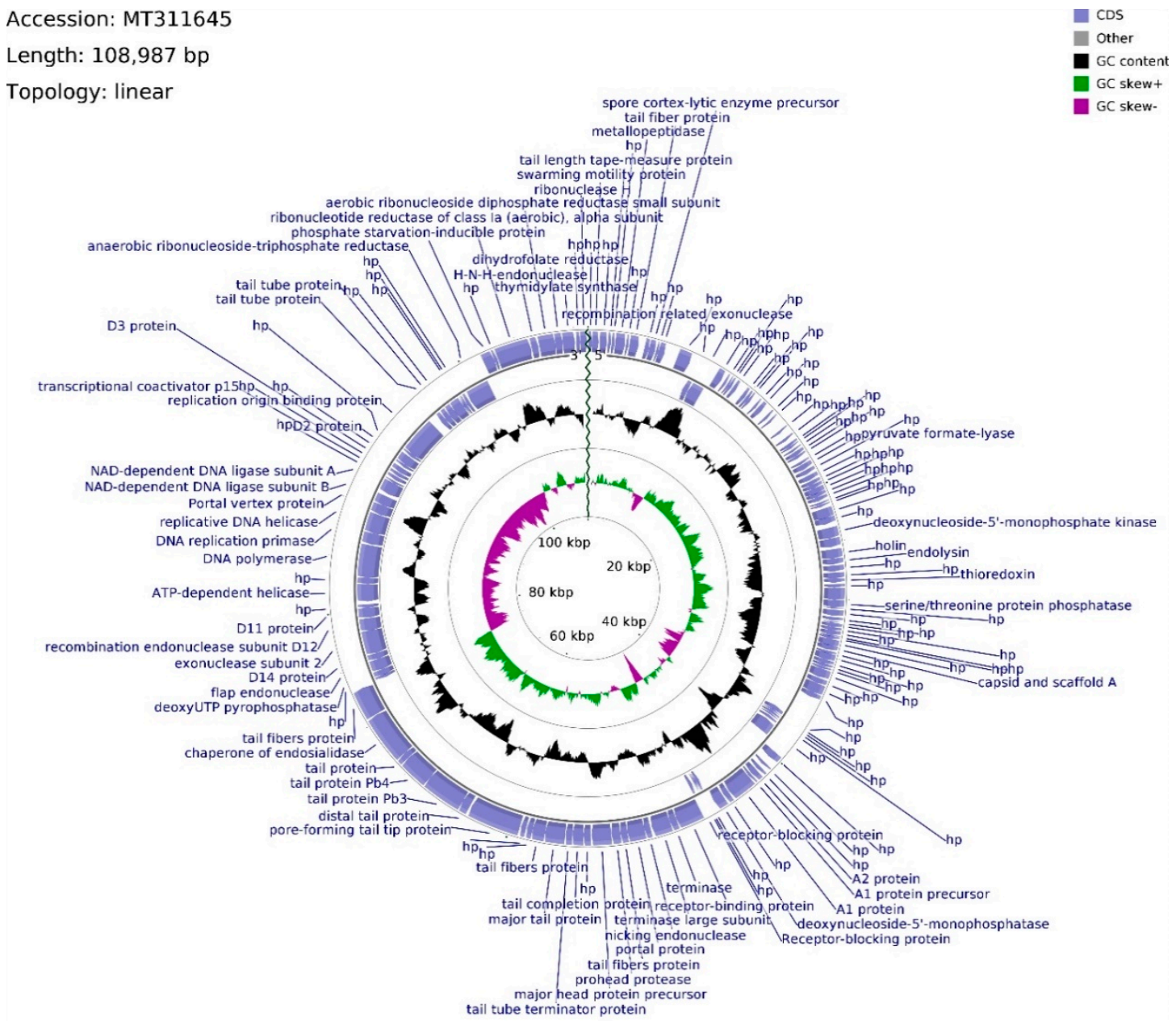

Figure 6. Schematic linear map of phage vB_Sen-E22 genome (ends of the genome are indicated by the wavy line). The inner rings show genome location, GC skew + (green) and - (purple) and GC content (black). The two most external rings show identified open reading frames (blue arrows) and results of genome annotation process.

Apart from ORF for potential nicking endonuclease (vB_SenE22_99), two terminase subunit ORFs are situated on the leading strand which are preceded by CDSs of three receptor-blocking proteins. Using Li's method, the DNA packaging of this phage can be suggested as operating by the COS mode. ORF for recombination-related exonuclease (vB_SenE22_12) is located upstream of the one for the hypothetical protein bearing PHB domain putatively engaged in phage decision between lytic and lysogenic growth. Within this domain, a Rho-independent terminator is located between vB_SenE22_12 and vB_SenE22_13 CDSs. The gap of the non-coding region encompasses $943 \mathrm{bps}$, whereas the average length of a gap between coding DNA sequences across the genome is equal to 93 bps. ORFs coding for proteins putatively involved in the process of DNA replication, located on the complementary strand, are assembled in a tile-like manner at the 80,720-90,335 bps region, with the putative replication origin binding protein ORF (vB_SenE22_141) situated upstream of the CDS conglomerate. vB_SenE22_141 (93,024-95,813 bp) overlaps with the vB_SenE22_140 hypothetical protein gene, bearing two transcription terminators starting at positions $117 \mathrm{bp}$ and $183 \mathrm{bp}$ inside the 234 bps long CDS. A transcription terminator can also be found within vB_SenE22_141 CDS, and downstream from the DNA ligase subunit B gene (vB_SenE22_132), which overlaps the A subunit ORF (vB_SenE22_133). The DNA replication tile is interlaced with the ORF encoding uncharacterized protein and the Portal vertex (vB_SenE22_131), belonging to the morphogenesis functional group. Between those sequences, there are ORFs for DNA helicase, DNA replication primase, and DNA 
polymerase, which are probably transcribed as two operons, as suggested by an overlap between start and stop codons with a 62 bps gap between vB_SenE22_129 and vB_SenE22_128. Based on the sequence analysis with PHACTS, this phage was non-confidently classified as lytic. Putative holin and endolysin CDSs (vB_SenE22_50 and vB_SenE22_51, respectively), representing genes coding for proteins involved in host cell lysis, overlap at positions $24,499-25,565 \mathrm{bps}$, shifting the probability of the lifestyle classification.

\subsection{Phylogenetic Analyses}

Comparisons of organizations of genomes of phages vB_Sen-TO17 and vB_Sen-E22 to genomes of the most related bacteriophages (according to DNA sequence similarities of whole genomes) are indicated as EasyFig in Figure 7.

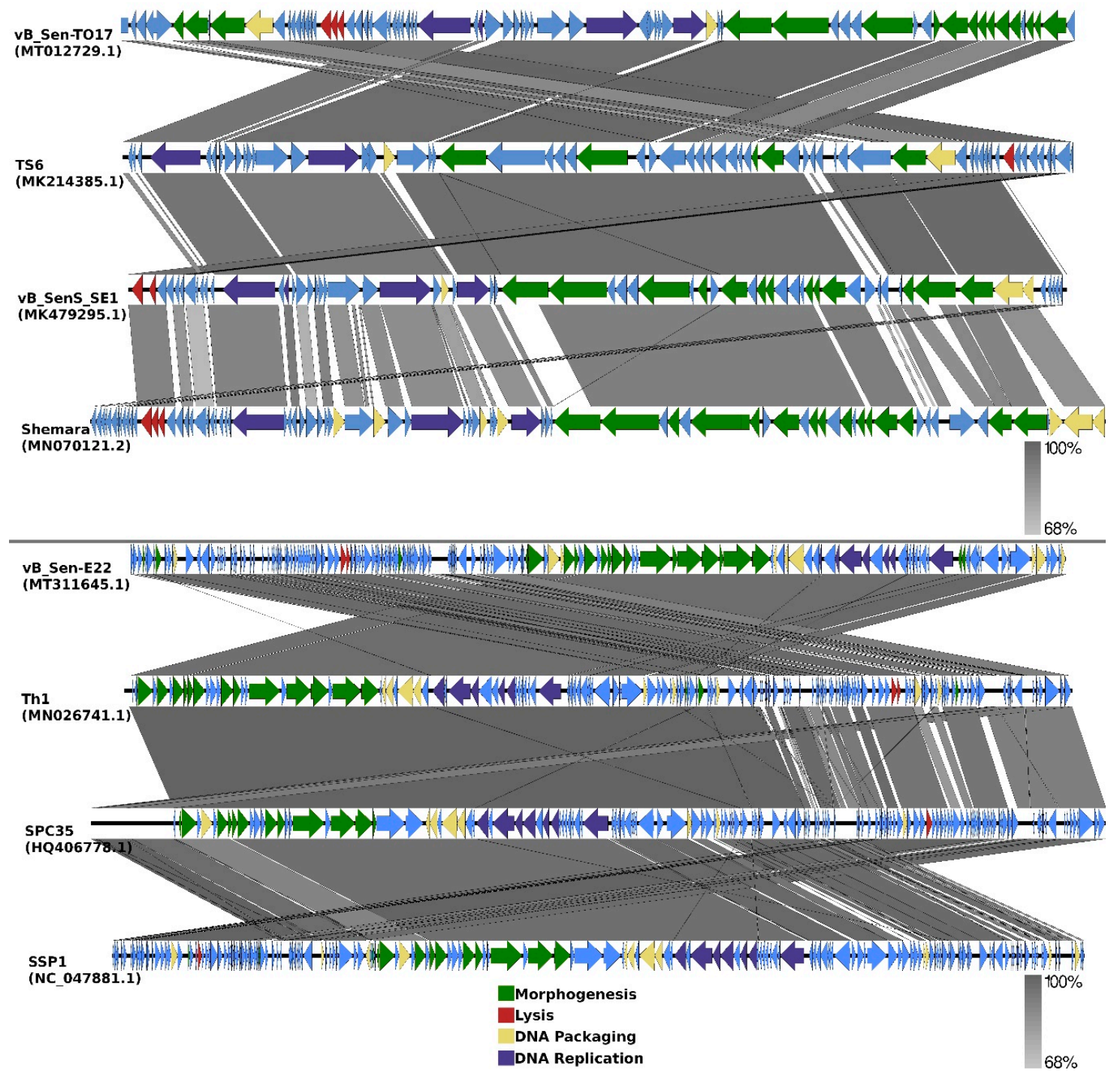

Figure 7. EasyFig output image of the genomic comparison between phages vB_Sen-TO17 and vB_Sen-E22, and the most closely related phages. Phage genomes are presented by linear visualization with coding regions shown as arrows. Selected open reading frames are colored in relation to their functions. The percentage of sequence similarity is indicated by the intensity of the gray color.

To analyse phylogenetic relationships between phage vB_Sen-TO17 and other viruses, we have compared the nucleotide sequences of the gene of the terminase large subunit and the nucleotide 
sequences of two additional markers such as genes encoding the portal protein and the major capsid protein of vB_Sen-TO17 with the respective sequences of other phages (Figure 8). The use of only the large terminase subunit gene sequence was insufficient to show the actual phylogenetic position of vB_Sen-TO17. The analysis of the nucleotide sequence of the gene coding for portal protein indicated that phage vB_Sen-TO17 is a sister to phage vB_SenS_SE1 (MK479295.1) with high bootstrap support $(B S=99)$. On the other hand, as shown in Figure 8, the analysis of the major capsid protein gene together with the combined analysis of three marker genes' sequences (TLS, $P P, M C P$ ) indicated a close relationship of vB_Sen-TO17 to phages vB_SenS_SE1 (MK479295.1) and TS6 (MK214385.1) with high bootstrap support of BS $=90$ and BS $=96$, respectively. Both phages belong to the family Siphoviridae, genus Cornellvirus. Sequence similarity searches of these phages demonstrated very high level of genome sequence identity with vB_Sen-TO17 ( 96\% and $\sim 98 \%$, respectively). The above results were confirmed by the whole-genome phylogenetic analysis and the whole-genome alignments constructed using the Mauve algorithm (see Section 4.15 for details), which indicated a high level of homology between these genomes (Figure 8). Nevertheless, one should note some differences in the trees topology obtained with the use of various methods presented above, for example in the position of Shemara phage (MN070121.2).

To analyse phylogenetic relationships between phage vB_Sen-E22 and other viruses, we compared the nucleotide sequence of the gene coding for the large terminase subunit of vB_Sen-E22 with the sequences of genes of the large terminase subunit of other phages. As shown in Figure 9, the sequence of the large terminase subunit gene of $\mathrm{vB}$ _Sen-E22 indicates its relationship to Shigella phage SSP1 (NC_047881.1) with low bootstrap support BS $=63$. On the other hand, the sequence similarity searches revealed that these phages show a very high level of genome sequence identity $(\sim 97 \%)$. The whole genome sequence analysis indicated that the phage vB_Sen-E22 is a sister to the phages Th1 (NC_048795.1) and SPC35 (HQ406778.1), with the highest BS = 100 in both cases (Figure 9). Phages SSP1, Th1, and SPC35 belong to the family Demerecviridae, genus Tequintavirus. Sequence similarity searches between Th1, SPC35, and phage vB_Sen-E22 demonstrated a very high level of identity ( $\sim 97 \%$ when comparing vB_Sen-E22 with Th1, and $\sim 96 \%$ when comparing vB_Sen-E22 with SPC35). The whole-genome alignments constructed using the Mauve algorithm (see Section 4.15 for details) also revealed a high level of homology between these genomes (Figure 9). Therefore, for vB_Sen-E22, the single marker gene phylogenetic analysis was insufficient and did not reflect the actual genetic position of this phage, probably due to mosaicism of phage genomes and a horizontal gene transfer. Nevertheless, the whole genome sequence phylogenetic analysis allowed us to obtain reliable results, leading to the proposal that vB_Sen-E22 belongs to the family Demerecviridae, genus Tequintavirus. 


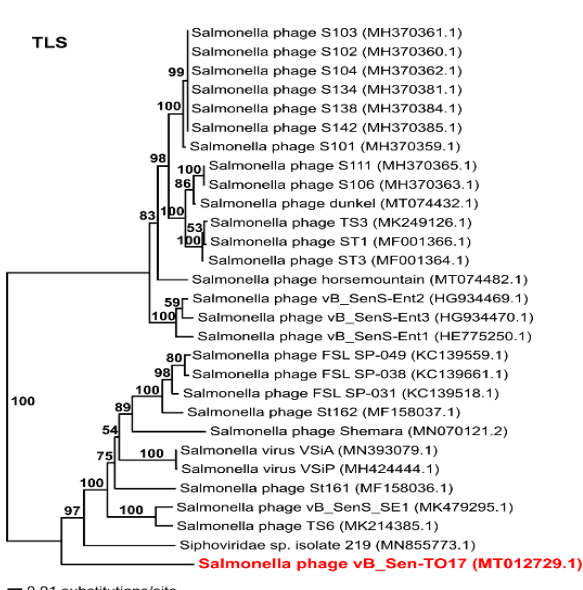

-0.01 substitutions/sitie

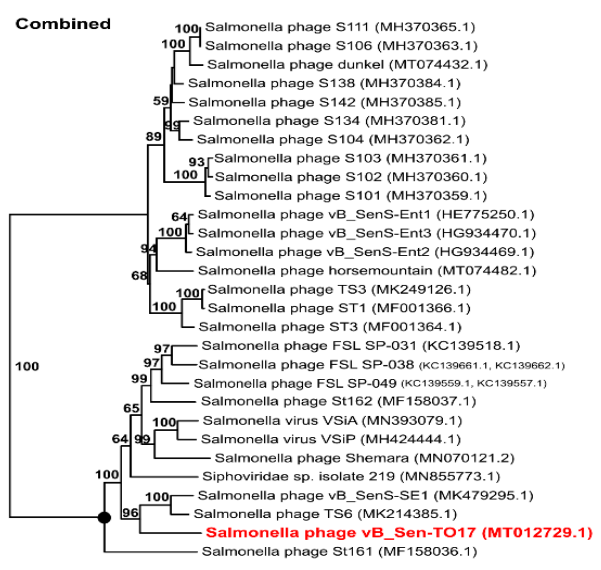

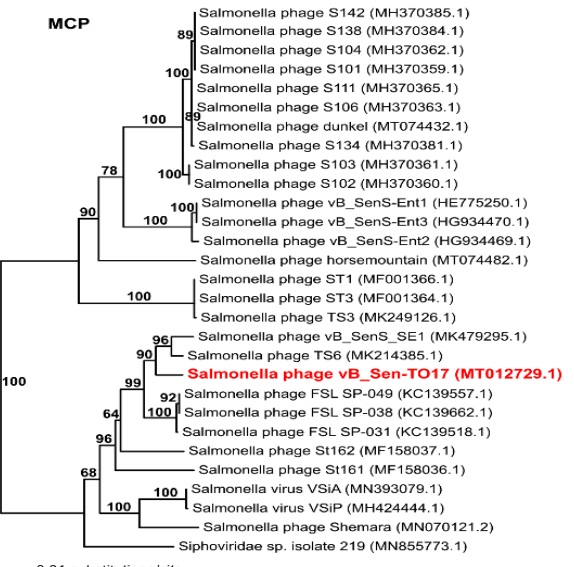

$-0.101$

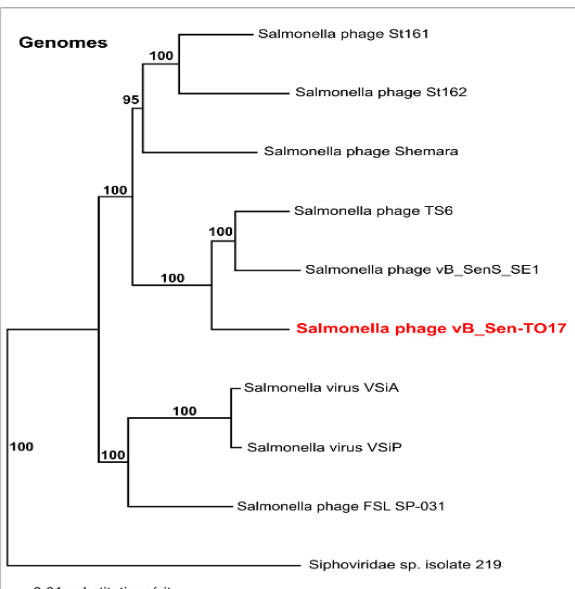

- 0.01 substitutions/sito
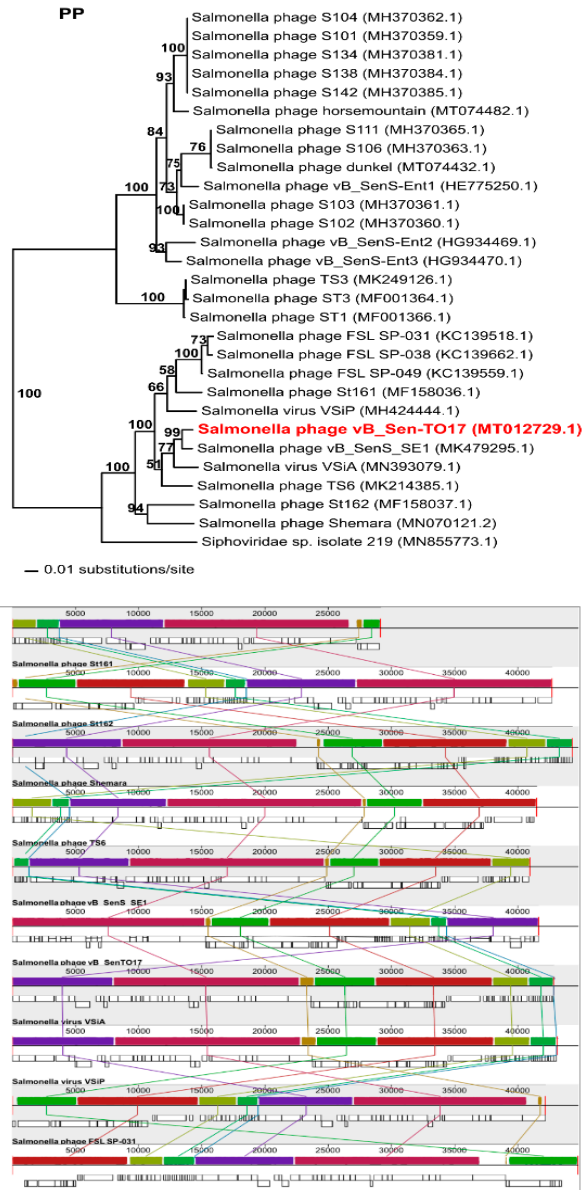

(1)

Figure 8. Neighbour-joining phylogenetic trees showing the phylogenetic position of phage vB_Sen-TO17 (in red color) within Cornellvirus based on the sequences coding for terminase large subunit (TLS), major capsid protein (MCP), portal protein (PP), their combined nucleotide sequences (Combined), as well as on the whole-genome analysis (Genomes). The reference sequences were collected from the NCBI database. The tree was constructed using PAUP *. Bootstrap value $>50 \%$, calculated based on 1000 resamplings, is shown above the branches. 

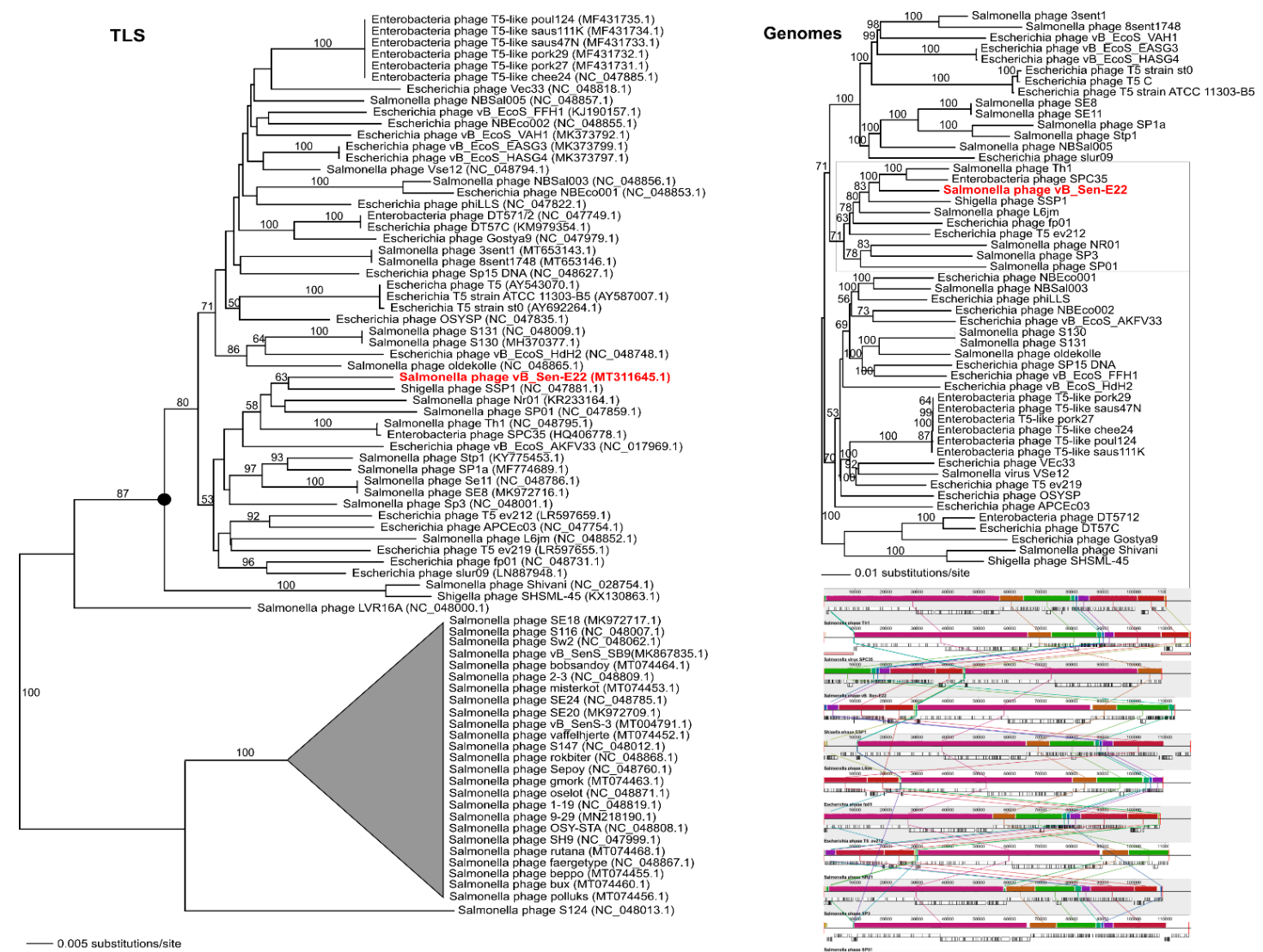

Figure 9. Neighbour-joining phylogenetic tree showing the phylogenetic position of phage vB_Sen-E22 (in red color) within Tequintavirus, based on the sequence coding for terminase large subunit (TLS), as well as on the whole-genome analysis (Genomes). The reference sequences were collected from the NCBI database. The tree was constructed using PAUP *. Bootstrap value $>50 \%$, calculated based on 1000 resamplings, is shown above branches.

\section{Discussion}

Among foodborne pathogens, S. enterica is one of the most frequently occurring infectious agents, and a majority of infections arise from contamination of poultry-derived products $[1,2]$. Antibiotic resistance occurs commonly in this bacterium; thus, alternative methods of eradication of this pathogenic microorganism are required [3]. One might consider that anti-Salmonella phage therapy could be a potential option to eliminate S. enterica from poultry, including both gastrointestinal tract of birds and poultry-derived products. On the other hand, effective phage therapy requires specific conditions to be applied in practice [35]. Since each phage is specific to particular serovars or strains, a large collection of bacteriophages is required for effective phage therapy. Since temperate phages can lysogenize bacterial cells, virulent bacteriophages are preferred to eradicate pathogenic bacteria. It is also crucial that genomes of bacteriophages used in phage therapy are devoid of any genes coding for toxins or other proteins which are detrimental for humans or animals. Finally, phages revealing rapid and effective development are preferred in phage therapy as they may eliminate target bacteria in a relatively short time. Therefore, isolation and characterization of a large set of different bacteriophages infecting S. enterica is desirable if phage therapy against this bacterium can be used in practice.

In this report, we describe isolation and characterization of two bacteriophages infecting S. enterica. The viruses (named vB_Sen-TO17 and vB_Sen-E22) were newly isolated from chicken feces and both molecular and functional characterization has been performed. Despite considerable differences in their genomes, including various sizes (41,658 bp for vB_Sen-TO17 and 108,987 bp for vB_Sen-E22) and organizations (Figure 7), both phages do not encode any homologs of known toxins or toxin 
motifs, reveal effective adsorption on host cells, and develop effectively in S. enterica cells giving burst sizes between 9 and $79 \mathrm{PFU} / \mathrm{cell}$, depending on the host strain, at $42^{\circ} \mathrm{C}$ (a temperature resembling that occurring naturally in chicken body). Moreover, their virions are relative stable under various conditions, including low $\mathrm{pH}$ (Table 3), presence of various solvents (Table 4) and different temperatures (Table 5). Although host ranges of tested phages are different, when considered together, their spectrum of sensitive S. enterica serovars is relatively large (Table 2). These features predispose vB_Sen-TO17 and $\mathrm{vB} \_$Sen-E22 to be used in phage therapy procedures.

Despite vB_Sen-E22 genome is about 2.6 times larger than that of vB_Sen-TO17 (108,987 bps vs. $41,658 \mathrm{bps})$, a diameter of the head of the former phage is only $10 \mathrm{~nm}$ bigger than that of the latter virus (58 vs. $48 \mathrm{~nm}$ ). Nevertheless, when calculating volumes of heads of these bacteriophages, one can estimate that they are about 101.8 thousand $\mathrm{nm}^{3}$ and about 57.7 thousand $\mathrm{nm}^{3}$ for vB_Sen-E22 and vB_Sen-TO17, respectively. Therefore, the genome of vB_Sen-E22 must be only moderately more densely packaged inside the head than that of vB_Sen-TO17.

Genomic analyses, performed with using the PHACTS algorithm (see Section 4.14), suggested that vB_Sen-TO17 might be a temperate phage. On the other hand, absence of genes with clear homology to those coding for integration and immunity proteins makes such a possibility doubtful. Moreover, the prediction that this might be a temperate phage was not confirmed by experimental results. The vB_Sen-TO17 virus forms clear plaques (Figure 1 and Table 1) and was found to be unable to lysogenize host cells under laboratory conditions. Therefore, we assume that a halo visible around plaques of this phage may arise from activities of lytic enzymes which if released from lysed cells and remining relatively stable in the agar, might cause inhibition of growth of uninfected bacteria neighboring lysed ones. Since vB_Sen-TO17 encodes 3 lytic enzymes, lysin/lysozyme (vB_SenTO17_19), putative holin-like class I (vB_SenTO17_20), and putative holin (vB_SenTO17_21), such hypothesis appears to be of high probability. Therefore, we conclude that it is a virulent rather than temperate phage, while genomic analyses might indicate features of its ancestors, and corresponding genes may be either inactive now or play different roles in phage development.

Bacteriophage vB_Sen-E22 also forms clear plaques but without halo (Figure 1 and Table 1). Moreover, its genome is characteristic for virulent phages, confirming that this virus is unable to form prophages in infected bacteria.

Molecular phylogenetic studies were somewhat complicated in the case of vB_Sen-TO17, as the analysis of the gene encoding large terminase subunit (classical molecular marker for such analyses in studies on bacteriophages) was not sufficient to determine the actual phylogenetic position of this phage. Nevertheless, comparisons of sequences of two additional genes allowed us to indicate that vB_Sen-TO17 is closely related to two other phages, vB_SenS_SE1 and TS6, which belong to the family Siphoviridae and genus Cornellvirus. Since sequence similarity searches indicated a high level of identity to vB_Sen-TO17, about $96 \%$ and about $98 \%$, respectively, we propose to classify the newly isolated phage to family Siphoviridae and genus Cornellvirus. This conclusion was corroborated by whole-genome phylogenetic analysis.

Phylogenetic analyses of vB_Sen-E22 were also not obvious and easy, as similarity of its large terminase subunit gene did not reveal high identity with any other phage. The analyses indicated its relationship to Shigella phage SSP1; however, the bootstrap support was relatively low $(B S=62)$. Nevertheless, since whole genome sequence identity between these two phages is at the level of $97 \%$, and such a level of similarity occurs also when comparing two other phages closely related to vB_Sen-E22, Th1, and SPC35, which belong to family Demerecviridae and genus Tequintavirus, we propose to classify vB_Sen-E22 to the same family and genus.

In conclusion, our studies, presented in this report, indicate that newly isolated and characterized bacteriophages vB_Sen-TO17 and vB_Sen-E22 can be used for further studies on anti-Salmonella phage therapy, particularly for eradication of E. enterica from poultry. 


\section{Materials and Methods}

\subsection{Bacterial Strains}

Strains of S. enterica, used in this study, come from the National Salmonella Center at Medical University of Gdansk (Gdansk, Poland). Strains of Proteus vulgaris, Citrobacter freundii, Enterococcus faecalis, and Escherichia coli come from the Department of Molecular Biology of the University of Gdansk collection of microorganisms (Gdansk, Poland). Staphylococcus aureus strain $6538^{\mathrm{TM}}$, Lactococcus lactis $49032^{\mathrm{TM}}$ and Lactobacillus acidophilus $314^{\mathrm{TM}}$ come from ATCC.

\subsection{Bacterial Culture Conditions}

Bacteria were cultured at $37^{\circ} \mathrm{C}$ or $42^{\circ} \mathrm{C}$. LB-medium (BioShop, Burlington, ON, Canada) was used to cultivate Gram-negative bacteria. For S. aureus, E. faecalis, L. lactis, and L. acidophilus, a BHI medium (Graso Biotech, Starogard Gdański, Poland) was used. Bacteriological agar (BioShop, Burlington, ON, Canada) at a final concentration of $1 \%$ was used in solidified media (LB-agar or BHI-agar). L. lactis and L. acidophilus were cultivated under microaerophilic conditions using the GenBox microaer system (BioMérieux, Marcy l'Etoile, France).

\subsection{Isolation and Purification of Phages vB_Sen-TO17 and vB_Sen-E22}

Chicken feces were suspended in an LB medium at a 1:10 ratio, homogenized using hand homogenizer (GenoPlast Biochemicals, Rokocin, Poland), and incubated overnight at $37^{\circ} \mathrm{C}$ (Heraeus B-12, Kendro Laboratory Products, Langenselbold, Germany). The samples were then centrifuged at $6000 \times \mathrm{g}$ for $20 \mathrm{~min}$ at $4{ }^{\circ} \mathrm{C}$ (Avanti JXN-26, rotor JS-13.1, Beckman Coulter, Indianapolis, USA), and supernatants were collected and filtered through a $0.22 \mu \mathrm{m}$ syringe filter (Millex-GP, Sigma-Aldrich, USA). Ten-fold dilutions were prepared in an LB medium and $100 \mu \mathrm{L}$ of each dilution was mixed with $200 \mu$ of bacterial host culture and $4 \mathrm{~mL}$ of LB with $0.7 \%$ agar. The mixture was poured onto plates containing $20 \mathrm{~mL}$ of LB-agar. The double-layer agar plates were incubated at $42{ }^{\circ} \mathrm{C}(\mathrm{BF} 53$, BINDER GmbH, Tuttlingen, Germany) overnight and then scanned for plaques. Different looking plaques were then collected, transferred to $10 \mathrm{~mL}$ of freshly diluted (1:100 ratio) host strain culture, and incubated with shaking at $155 \mathrm{rpm}$ for $3 \mathrm{~h}$ at $42^{\circ} \mathrm{C}$ (OLS 200, Grant Instruments, Sherpeth, UK). Obtained lysates were treated with $5 \mathrm{~mL}$ chloroform (Alchem, Torun, Poland), centrifuged (4000× g, 10 $\min , 4^{\circ} \mathrm{C}$ ), and filtered through $0.22 \mu \mathrm{m}$ filter. The lysates were then titrated on double-layer agar plates. The plates were incubated overnight at $42{ }^{\circ} \mathrm{C}$ and then scanned for uniform plaques. The purity of lysates was also checked using electron microscopy.

\subsection{Phage Propagation}

A $10 \mathrm{~mL}$ amount of bacterial host culture, grown overnight in LB medium, was added to $1 \mathrm{~L}$ of LB and incubated at $37^{\circ} \mathrm{C}$ with agitation at $150 \mathrm{rpm}$. At $\mathrm{OD}_{600}=0.15$ (measured by using SmartSpec PLUS, BIO-RAD, CA, USA) bacteria were infected with phages at a multiplicity of infection (m.o.i.) of 0.5 and incubated at $37^{\circ} \mathrm{C}$ until lysis occurred. For phage purification, polyethylene glycol (PEG) 8000 (BioShop, Burlington, Ontario, Canada) was added to the final concentration of $10 \%$ and stirred (Carl Roth, Karlsruhe, Germany) overnight at $4{ }^{\circ} \mathrm{C}$. The precipitate was collected by centrifugation at $10,000 \times \mathrm{g}$ for $30 \mathrm{~min}$ at $4{ }^{\circ} \mathrm{C}$ (Avanti JXN-26, rotor JLA-8000, Beckman Coulter, IN, USA) and suspended in $0.89 \% \mathrm{NaCl}$ (Alchem, Torun, Poland). PEG 8000 was removed by adding $2 \mathrm{~mL}$ of chloroform and centrifugation at $4000 \times \mathrm{g}$ for $15 \mathrm{~min}$ at $4{ }^{\circ} \mathrm{C}$ (Avanti JXN-26, rotor JS-13.1, Beckman Coulter, IN, USA). The procedure was repeated until no PEG 8000 precipitate could be observed.

\subsection{Electron Microscopy}

Phages were purified by centrifugation using $\mathrm{CsCl}$ (Sigma Aldrich, MO, USA) density gradient as described previously [36]. Transmission electron microscopy analysis of phage capsids was performed 
in the Laboratory of Electron Microscopy, Faculty of Biology, University of Gdansk, Gdansk, Poland. Virions were negatively stained with uranyl acetate (VWR International Ltd., Radnor, PA, USA) and then micrographs were taken under a Tecnai G2 Spirit BioTWIN electron microscope (FEI, Thermofisher Scientific, OR, USA).

\subsection{Plaque Morphology Assessment}

The plaque morphology analysis of bacteriophages was performed using $S$. Typhimurium 13 as a host. Ten-fold dilutions of phage lysate were prepared in $0.89 \% \mathrm{NaCl} ; 200 \mu \mathrm{L}$ of overnight host culture were mixed with $10 \mu \mathrm{L}$ of an appropriate dilution of phage lysate and added to $4 \mathrm{~mL}$ of $\mathrm{LB}$ with $0.7 \%$ agar. The mixture was poured onto plates containing $20 \mathrm{~mL}$ of LB agar. The double-layer agar plates were incubated at $42{ }^{\circ} \mathrm{C}$ for $16 \mathrm{~h}$. Plaque morphology and diameter were determined.

\subsection{Determination of Phage Host Range and Efficiency of Lysogenization}

Host range of bacteriophages was determined using the spot-test method described previously [34], with some modifications. Ten-fold dilutions of phage stocks were prepared in $0.89 \% \mathrm{NaCl} ; 10 \mu \mathrm{L}$ of the appropriate dilution was mixed with $200 \mu \mathrm{L}$ of overnight bacterial culture and $4 \mathrm{~mL}$ of LB with $0.7 \%$ agar. Plates were incubated overnight at $37^{\circ} \mathrm{C}$ and then scanned for plaques.

For lysogenization experiments, S. Agona 1408, S. Dublin 65, S. Enteritidis 64, S. Enteritidis 1392, S. Heidelberg 16, S. Infantis 165, S. Newport 50, S. Typhimurium 12, S. Typhimurium 13, and S. Virchow 41 were cultivated to $\mathrm{OD}_{600}=0.2$ at $42{ }^{\circ} \mathrm{C}$. Then, a sample of $1 \mathrm{~mL}$ of bacterial culture was centrifuged $\left(2000 \times \mathrm{g}, 10 \mathrm{~min}, 4^{\circ} \mathrm{C}\right)$ and the pellet was resuspended in $1 \mathrm{~mL}$ of $0.5 \times \mathrm{LB}$ medium. Following incubation for $5 \mathrm{~min}$ at $30^{\circ} \mathrm{C}$, phage lysate was added to m.o.i. $=1$. In the control variant of the experiment, $0.5 \times \mathrm{LB}$ was added instead of phage lysate. Bacteria were incubated for $3 \mathrm{~h}$ at $30^{\circ} \mathrm{C}$, and then centrifuged $\left(4000 \times g, 5 \mathrm{~min}, 4^{\circ} \mathrm{C}\right)$ in order to remove free phage particles. Supernatant was discarded, and the pellet was resuspended in a fresh LB medium. Serial dilutions were prepared in $0.89 \% \mathrm{NaCl}$ and $30 \mu \mathrm{L}$ of each dilution was spread onto LB plates. After $24 \mathrm{~h}$ incubation at $30{ }^{\circ} \mathrm{C}$, 96 colonies were passaged separately, each in a well of a 96-well plate with $150 \mu \mathrm{L}$ of LB medium. The plates were incubated with shaking at $42{ }^{\circ} \mathrm{C}$ until bacteria culture reached $\mathrm{OD}_{600}=0.2$.

For estimation of efficiency of lysogenization, mitomycin $C$ was added (to a final concentration of $1 \mu \mathrm{g} / \mathrm{mL}$ ) to $150 \mu \mathrm{L}$ of bacterial culture derived from a single tested colony (this antibiotic had been demonstrated previously to induce prophages in S. enterica [37-39]). The plates were then incubated for $3 \mathrm{~h}$. Afterwards, $10 \mu \mathrm{L}$ of chloroform was added, the plates were centrifuged $\left(2000 \times \mathrm{g}, 10 \mathrm{~min}, 4^{\circ} \mathrm{C}\right)$, and $5 \mu \mathrm{L}$ of water phase was spotted onto double-layer LB agar plates. The plates were incubated overnight at $42{ }^{\circ} \mathrm{C}$ and then scanned for plaques. A colony was determined as lysogenic if plaques were formed on bacterial lawn. The efficiency of lysogenization was determined as a percent of lysogens among all tested bacterial colonies. The experiment was performed in triplicate.

In order to test the resistance to superinfection, $50 \mu \mathrm{L}$ of bacterial culture was mixed with $4 \mathrm{~mL}$ of $0.7 \% \mathrm{LB}$ agar and poured onto an LB agar plate. Then, $2.5 \mu \mathrm{L}$ of phage lysate was spotted on top of it. The plates were incubated overnight at $42{ }^{\circ} \mathrm{C}$ and scanned for plaques. If plaques were not visible, the clone was recognized as resistant to phage. The resistance to infection was determined as a percent of bacteria not infected by the phage. The experiments were performed in triplicates.

\subsection{Phage Sensitivity to Various Conditions}

Sensitivity of phages to low $\mathrm{pH}$ conditions was performed as described previously [21]. Briefly, $100 \mu \mathrm{L}$ of phage lysate were added to $900 \mu \mathrm{L}$ of $\mathrm{LB}$ at $\mathrm{pH} 1.8,2.0,2.2,2.5,2.8,3.0,10.0$, and 12.0, with $\mathrm{pH} 7.0$ used as a control variant. The $\mathrm{pH}$ was adjusted by addition $1 \mathrm{M} \mathrm{HCl}$ (Alchem, Torun, Poland) or $1 \mathrm{M} \mathrm{NaOH}$ (Alchem, Torun, Poland) and measured using a $\mathrm{pH}$ meter ( $\mathrm{pH} 50+\mathrm{DHS}$, Giorgio Bormac, Carpi, Italy). Samples were mixed and incubated for $1 \mathrm{~h}$ at $42{ }^{\circ} \mathrm{C}$. Afterwards, samples were serially diluted and overlaid on top of LB agar plates with the top agar containing $200 \mu \mathrm{L}$ of overnight bacterial culture. Plates were incubated overnight at $37^{\circ} \mathrm{C}$ and then scanned for plaques. Susceptibility 
to disinfectants, liquid media, and buffers were performed in accordance with a procedure described previously [34,37]. Briefly, $100 \mu \mathrm{L}$ of phage lysate was added to $900 \mu \mathrm{L}$ of tested solution. The samples were mixed and incubated for $1 \mathrm{~h}$ at $25^{\circ} \mathrm{C}$ or for $24 \mathrm{~h}$ at $37^{\circ} \mathrm{C}$ for DMEM (Thermo Fisher Scientific Inc., Paisley, UK), supplemented with 10\% fetal bovine serum (Thermo Fisher Scientific Inc., Paisley, UK) and $1 \%$ antibiotic/antimycotic solution (Sigma Aldrich Co. LLC., St. Louis, MO, USA). The experiments were performed in triplicates.

\subsection{Phage Sensitivity to Different Temperatures}

Phage survivability at different temperatures was assessed in accordance with previously described protocol [34]. Phages were diluted in $0.89 \% \mathrm{NaCl}$ to a final concentration of $10^{9} \mathrm{PFU} / \mathrm{mL}$ and then incubated at temperature $-80^{\circ} \mathrm{C}$ (Revco ULT-1790-10V, Thermo Fisher Scientific, OR, USA), $-20^{\circ} \mathrm{C}$, $4{ }^{\circ} \mathrm{C}, 25^{\circ} \mathrm{C}, 37^{\circ} \mathrm{C}, 42{ }^{\circ} \mathrm{C}, 60^{\circ} \mathrm{C}$, or $95^{\circ} \mathrm{C}$ for a given period of time. Following the incubation, 10 -fold dilutions were prepared in $0.89 \% \mathrm{NaCl}$ and overlaid on top of double agar plates. The plates were incubated at $42{ }^{\circ} \mathrm{C}$ overnight and then scanned for plaques. The percent of surviving phages was calculated as a ratio of surviving phages to phage titer before incubation. The experiments were done in triplicates.

\subsection{Efficiency of Phage Plating at Different Temperatures}

The analysis of phage titration dependence on temperature was performed in accordance with previously described protocol [34]. Briefly, 10-fold dilutions of phage lysates were prepared in $0.89 \%$ $\mathrm{NaCl}$ and overlaid on top of double agar plates. The plates were incubated at $20^{\circ} \mathrm{C}, 25^{\circ} \mathrm{C}, 37^{\circ} \mathrm{C}$, and $42^{\circ} \mathrm{C}$ overnight. The efficacy of phage plating was assessed by comparison of phage titers obtained at different temperatures. The experiments were performed in triplicates.

\subsection{Efficiency of Phage Adsorption}

An adsorption assay was performed according to the protocols described previously [40], with some modifications. Overnight cultures of bacterial strains were diluted 1:100 in fresh LB medium and incubated with shaking at $42{ }^{\circ} \mathrm{C}$ until $\mathrm{OD}_{600}=0.2$ was reached. Then, $2 \mathrm{~mL}$ samples were centrifuged at $2000 \times g, 5 \mathrm{~min}, 4^{\circ} \mathrm{C}$ (MiniSpin Plus, Eppendorf, Hamburg, Germany) and the pellet was suspended in $1 \mathrm{~mL}$ of fresh LB medium. After $10 \mathrm{~min}$ incubation at $42{ }^{\circ} \mathrm{C}$, phages were added to final m.o.i. of 0.1 . At given time points, $100 \mu \mathrm{L}$ samples were collected and centrifuged at $6000 \times g$ for $30 \mathrm{~s}$. Ten-fold dilutions were prepared and overlaid on top of double-layer agar plates containing $0.7 \%$ LB agar with $200 \mu \mathrm{L}$ of bacterial host culture. The number of viruses mixed with bacterial host cells at time 0 was considered $100 \%$ non-adsorbed phages. Other values were compared to this sample. The experiment was performed in triplicates.

\subsection{One-Step Growth Experiments}

One-step growth experiments were performed as described previously [21], with some modifications. Bacteria were grown at $42{ }^{\circ} \mathrm{C}$ until reaching optical density of $\mathrm{OD}_{600}=0.1$. Then, $10 \mathrm{~mL}$ of bacterial culture were centrifuged $\left(4000 \times g, 10 \mathrm{~min}, 4^{\circ} \mathrm{C}\right.$ ) (Avanti JXN-26, rotor JS-13.1, Beckman Coulter, Indianapolis, USA), and the pellet was suspended in $1 \mathrm{~mL}$ of LB medium at $4{ }^{\circ} \mathrm{C}$. Phages were added to the host culture at m.o.i. $=0.1$ and allowed to adsorb for $5 \mathrm{~min}$ at $42{ }^{\circ} \mathrm{C}$. The mixture was centrifuged at $4,000 \times \mathrm{g}$ for $10 \mathrm{~min}$ at $4{ }^{\circ} \mathrm{C}$ to remove unadsorbed phage particles. After centrifugation, $50 \mu \mathrm{L}$ of phage-bacteria mixture was added to $20 \mathrm{~mL}$ of LB medium (time 0 ) and cultivated at $42{ }^{\circ} \mathrm{C}$. The number of infective centers was estimated from samples taken $1 \mathrm{~min}, 2.5 \mathrm{~min}$, and $5 \mathrm{~min}$ after infection, by mixing $10 \mu \mathrm{L}$ of sample with $200 \mu \mathrm{L}$ of overnight bacterial culture and $4 \mathrm{~mL}$ of $0.7 \% \mathrm{LB}$ agar. Samples $(100 \mu \mathrm{L}$ each) were collected at given temperatures, mixed with $50 \mu \mathrm{L}$ of chloroform, cleared by centrifugation $(6000 \times g, 30 \mathrm{sec}$ ) (MiniSpin Plus, Eppendorf, Hamburg, Germany), and titrated to determine the number of PFU $/ \mathrm{mL}$. Simultaneously, $100 \mu \mathrm{L}$ samples were collected, centrifuged immediately $(6000 \times g, 30 \mathrm{~s})$, and titrated. The plates were incubated at $42^{\circ} \mathrm{C}$ overnight. The experiment 
was performed in triplicates. Burst size was calculated as the ratio of phage titer from samples untreated with chloroform to the number of infection centers. Total phage yield was calculated as the ratio of phage titer from chloroform-treated samples to the number of infection centers.

\subsection{Phage DNA Isolation}

Phage lysate, purified as described in Section 4.5, was treated with DNase I (1 U/ $\mu \mathrm{L}$; Thermo Fisher Scientific Inc., Paisley, UK) and RNase A ( $5 \mu \mathrm{g} / \mu \mathrm{L}$; Thermo Fisher Scientific Inc., Paisley, UK) to degrade bacterial nucleic acids. To digest the exogenous DNA and RNA, the mixture was incubated for $30 \mathrm{~min}$ at $37^{\circ} \mathrm{C}$. Then, DNase I and RNase A were inactivated by heating to $95^{\circ} \mathrm{C}$ and 5 min incubation. Genomic DNA of phages was isolated with a MasterPure ${ }^{\mathrm{TM}}$ Complete DNA and RNA Purification Kit (Epicentre Biotechnologies, WI, USA) in accordance with the manufacturer's guidelines.

\subsection{Genomic Analysis of Phages vB_Sen-E22 and vB_Sen-TO17}

Genomes of vB_Sen-E22 and vB_Sen-TO17 phages were sequenced using the Whole Genome Shotgun (WGS) strategy and run on the MiSeq Illumina platform. Samples for next-generation sequencing were prepared according to the NEBNext DNA Library Prep Master Mix Set for the Illumina manual with random selection. The read length interval ranged from 36 to $251 \mathrm{bp}$. Raw reads were deposited in SRA databases under BioProject ID: PRJNA671789.

Annotation and sequence analysis was conducted as described previously [21]. Briefly, annotation was based on open reading frame prediction obtained via the RASTtk toolkit [41] and the Prokka suite containing Prodigal [42] where points of difference were settled by analysis of Ribosome Binding Sites (RBS) 4-12 nucleotides upstream of start codons. Putative functions of ORFs were assessed employing the Nucleotide Collection (nr/nt) database with the CDD database [43], 97 Salmonella phage genomes from pVOGs database (http://dmk-brain.ecn.uiowa.edu/pVOGs/, last accessed on 16 November 2020), and the HMMer Reference Proteomes database [44]. Phage-specific promoters were predicted by using the Neural Network Promoter Prediction NNPP method (http://www.fruitfly.org/seq_tools/ promoter.html, last accessed on 16 November, 2020). To find Rho-independent terminators in nucleic acid sequences, the Arnold tool was employed [45]. Classification of phages lifestyle was predicted using PHACTS [46]. For phage genome termini analysis, packing mode and topology of viral genomes PhageTerm was employed [47]. To create maps of viral genomes, the CGView Comparison Tool [48] was used, with additional GC skew and GC content analysis. Comparison of genomes of related phages was performed using the EasyFig program (http://mjsull.github.io/Easyfig/files.html, last accessed on 14 August 2020).

\subsection{Phylogenetic Analysis of Phages vB_Sen-E22 and vB_Sen-TO17}

To estimate the phylogenetic positions of the newly isolated phages vB_Sen-E22 and vB_Sen-TO17, the nucleotide sequences of the terminase large subunit gene (genetic marker for the order Caudovirales) were compared with the sequences of other reference bacteriophages that were deposited in the NCBI database. We have also compared the nucleotide sequences of genes coding for major capsid protein and portal protein of vB_Sen-TO17. DNA sequences were translated to amino acid, then aligned and adjusted by eye using Seaview [49]. Additionally, we conducted the whole-genome sequence phylogenetic analyses for both phages. Multiple genome alignments were conducted through the progressive Mauve algorithm [50]. Each subalignment generated by Mauve was adjusted by eye and concatenated using Seaview [49]. All matrices were analyzed using PAUP * (Phylogenetic Analysis Using Parsimony * and Other Methods) version 4.0a [51]. The optimality criterion was set to distance using the Neighbour-Joining algorithm (NJ). The p-distance was used based on a previously published recommendation [52]. The robustness of the tree topology was assessed by bootstrap analyses based on 1000 replicates. 
Supplementary Materials: The supplementary materials are available online at http://www.mdpi.com/1422-0067/ 21/22/8821/s1.

Author Contributions: Conceptualization, K.K.-K., G.W. and A.W.; methodology, K.K.-K., M.G. (Michał Grabski), M.G. (Marcin Górniak), and A.J.-K.; validation, K.K.-K. and M.G. (Michał Grabski); experimental investigation, K.K.-K., Ł.G. and M.K.; data analysis, K.K.-K., M.G. (Michał Grabski), M.G. (Marcin Górniak), A.J.-K. and A.W.; data interpretation, K.K.-K., M.G. (Michał Grabski), M.G. (Marcin Górniak), A.J.-K., G.W. and A.W.; writing-original draft preparation, K.K.-K. and A.W.; writing-review and editing, K.K.-K., M.G. (Michał Grabski), G.W. and A.W.; visualization, K.K.-K., M.G. (Michał Grabski) and M.G. (Marcin Górniak); supervision, A.W.; funding acquisition, A.W. All authors have read and agreed to the published version of the manuscript.

Funding: This research was funded by National Science Center (Poland), grant no. 2017/27/B/NZ9/00393.

Acknowledgments: The authors would like to thank Magdalena Narajczyk for making electron microscopic images, and Jakub Kaźmierczak for providing software enabling phage capsid measurements and help with its use.

Conflicts of Interest: The authors declare no conflict of interest. The funders had no role in the design of the study; in the collection, analyses, or interpretation of data; in the writing of the manuscript, or in the decision to publish the results.

\section{References}

1. Torres-Acosta, M.A.; Clavijo, V.; Vaglio, C.; González-Barrios, A.F.; Vives-Flórez, M.J.; Rito-Palomares, M. Economic evaluation of the development of a phage therapy product for the control of Salmonella in poultry. Biotechnol. Progr. 2019, 35, 2852. [CrossRef]

2. Clavijo, V.; Florez, M.J.V. The gastrointestinal microbiome and its association with the control of pathogens in broiler chicken production: A review. Poult. Sci. 2018, 97, 1006-1021. [CrossRef]

3. Gal-Mort, O.; Boyle, E.C.; Grassl, G.A. Same species, different diseases: How and why typhoidal and non-typhoidal Salmonella enterica serovars differ. Front. Microbiol. 2014, 5, 391. [CrossRef]

4. Davies, J.; Davies, D. Origins and evolution of antibiotic resistance. Microbiol. Mol. Biol. Rev. 2010, 74, 417-433. [CrossRef]

5. Okocha, R.C.; Olatoye, I.O.; Adedeji, O.B. Food safety impacts of antimicrobial use and their residues in aquaculture. Public Health Rev. 2018, 39, 21. [CrossRef] [PubMed]

6. Hutchings, M.; Truman, A.; Wilkinson, B. Antibiotics: Past, present and future. Curr. Opin. Microbiol. 2019, 51, 72-80. [CrossRef] [PubMed]

7. Bengtsson, B.; Greko, C. Antibiotic resistance-Consequences for animal health, welfare, and food production. Upsala J. Med. Sci. 2014, 119, 96-102. [CrossRef] [PubMed]

8. Ventola, C.L. The antibiotic resistance crisis: Part 1: Causes and threats. Pharm. Therapeut. 2015, 40, $277-283$.

9. Górski, A.; Międzybrodzki, R.; Jończyk-Matysiak, E.; Borysowski, J.; Letkiewicz, S.; Weber-Dabrowska, B. The fall and rise of phage therapy in modern medicine. Expert Opin. Biol. Ther. 2019, 19, 1115-1117. [CrossRef]

10. Górski, A.; Międzybrodzki, R.; Węgrzyn, G.; Jończyk-Matysiak, E.; Borysowski, J.; Weber-Dabrowska, B. Phage therapy: Current status and perspectives. Med. Resr Rev. 2020, 40, 459-463. [CrossRef]

11. Rohde, C.; Resch, G.; Pirnay, J.P.; Blasdel, B.G.; Debarbieux, L.; Gelman, D.; Górski, A.; Hazan, R.; Huys, I.; Kakabadze, E.; et al. Expert opinion on three phage therapy related topics: Bacterial phage resistance, phage training and prophages in bacterial production strains. Viruses 2018, 10, 178. [CrossRef] [PubMed]

12. Yan, T.; Liang, L.; Yin, P.; Zhou, Y.; Sharoba, A.M.; Lu, Q.; Dong, X.; Liu, K.; Connerton, I.F.; Li, J.; et al. Application of a novel phage LPSEYT for biological control of Salmonella in foods. Microorganisms 2020, 8, 400. [CrossRef] [PubMed]

13. Kakabadze, E.; Makalatia, K.; Grdzelishvili, N.; Bakuradze, N.; Goderdzishvili, M.; Kusradze, I.; Phoba, M.F.; Lunguya, O.; Lood, C.; Lavigne, R.; et al. Selection of potential therapeutic bacteriophages that lyse a CTX-M-15 extended spectrum $\beta$-lactamase producing Salmonella enterica serovar Typhi strain from the Democratic Republic of the Congo. Viruses 2018, 10, 172. [CrossRef] [PubMed]

14. Huang, C.; Virk, S.; Shi, J.; Zhou, Y.; Willias, S.P.; Morsy, M.K.; Abdelnabby, H.E.; Liu, J.; Wang, X.; Li, J.; et al. Isolation, characterization, and application of bacteriophage LPSE1 against Salmonella enterica in ready to eat (RTE) foods. Front. Microbiol. 2018, 9, 1046. [CrossRef] [PubMed]

15. Sritha, K.; Bhat, S.G. Genomics of Salmonella phage $\Phi$ Stp1: Candidate bacteriophage for biocontrol. Virus Genes 2018, 54, 311-318. [CrossRef] 
16. Chen, Y.; Sun, E.; Song, J.; Tong, Y.; Wu, B. Three Salmonella enterica serovar Enteritidis bacteriophages from the Siphoviridae family are promising candidates for phage therapy. Can. J. Microbiol. 2018, 6, 865-875. [CrossRef]

17. Patil, K.; Zeng, C.; O’Leary, C.; Lessor, L.; Kongari, R.; Gill, J.; Liu, M. Complete genome sequence of Salmonella enterica serovar Typhimurium siphophage Seabear. Microbiol. Resour. Announc. 2019, 8, e01160-19. [CrossRef]

18. Holguín, A.V.; Cárdenas, P.; Prada-Peñaranda, C.; Rabelo Leite, L.; Buitrago, C.; Clavijo, V.; Oliveira, G.; Leekitcharoenphon, P.; Møller Aarestrup, F.; Vives, M.J.; et al. Host resistance, genomics and population dynamics in a Salmonella Enteritidis and phage system. Viruses 2019, 11, 188. [CrossRef]

19. Bao, H.; Shahin, K.; Zhang, Q.; Zhang, H.; Wang, Z.; Zhou, Y.; Zhang, X.; Zhu, S.; Stefan, S.; Wang, R.; et al. Morphologic and genomic characterization of a broad host range Salmonella enterica serovar Pullorum lytic phage vB_SPuM_SP116. Microb. Pathog. 2019, 136, 103659. [CrossRef]

20. Mohamed, A.; Taha, O.; El-Sherif, H.M.; Connerton, P.L.; Hooton, S.P.T.; Bassim, N.D.; Connerton, I.; El-Shibiny, A. Bacteriophage ZCSE2 is a potent antimicrobial against Salmonella enterica serovars: Ultrastructure, genomics and efficacy. Viruses 2020, 12, 424. [CrossRef]

21. Kosznik-Kwaśnicka, K.; Ciemińska, K.; Grabski, M.; Grabowski, Ł.; Górniak, M.; Jurczak-Kurek, A.; Węgrzyn, G.; Węgrzyn, A. Characteristics of a series of three bacteriophages infecting Salmonella enterica strains. Int. J. Mol. Sci. 2020, 21, 6152. [CrossRef] [PubMed]

22. Sevilla-Navarro, S.; Marín, C.; Cortés, V.; García, C.; Vega, S.; Catalá-Gregori, P. Autophage as a control measure for Salmonella in laying hens. Poult. Sci. 2018, 97, 4367-4373. [CrossRef] [PubMed]

23. Tie, K.; Yuan, Y.; Yan, S.; Yu, X.; Zhang, Q.; Xu, H.; Zhang, Y.; Gu, J.; Sun, C.; Lei, L.; et al. Isolation and identification of Salmonella pullorum bacteriophage YSP2 and its use as a therapy for chicken diarrhea. Virus Genes 2018, 54, 446-456. [CrossRef] [PubMed]

24. Clavijo, V.; Baquero, D.; Hernandez, S.; Farfan, J.C.; Arias, J.; Arévalo, A.; Donado-Godoy, P.; Vives-Flores, M. Phage cocktail SalmoFREEßreduces Salmonella on a commercial broiler farm. Poult. Sci. 2019, 98, 5054-5063. [CrossRef]

25. Vaz, C.S.L.; Voss-Rech, D.; Alves, L.; Coldebella, A.; Brentano, L.; Trevisol, I.M. Effect of time of therapy with wild-type lytic bacteriophages on the reduction of Salmonella Enteritidis in broiler chickens. Vet. Microbiol. 2020, 240, 108527. [CrossRef]

26. Li, M.; Lin, H.; Jing, Y.; Wang, J. Broad-host-range Salmonella bacteriophage STP4-a and its potential application evaluation in poultry industry. Poult. Sci. 2020, 99, 3643-3654. [CrossRef]

27. Żbikowska, K.; Michalczuk, M.; Dolka, B. The use of bacteriophages in the poultry industry. Animals 2020, 10, 872. [CrossRef]

28. Nikkhahi, F.; Soltan Dallal, M.M.; Alimohammadi, M.; Rahimi Foroushani, A.; Rajabi, Z.; Fardsanei, F.; Imeni, S.M.; Torabi Bonab, P. Phage therapy: Assessment of the efficacy of a bacteriophage isolated in the treatment of salmonellosis induced by Salmonella Enteritidis in mice. Gastroenterol. Hepatol. Bed Bench 2017, 10, 131-136.

29. Tang, F.; Zhang, P.; Zhang, Q.; Xue, F.; Ren, J.; Sun, J.; Qu, Z.; Zhuge, X.; Li, D.; Wang, J.; et al. Isolation and characterization of a broad-spectrum phage of multiple drug resistant Salmonella and its therapeutic utility in mice. Microb. Pathog. 2019, 126, 193-198. [CrossRef]

30. Dallal, M.M.S.; Nikkhahi, F.; Alimohammadi, M.; Douraghi, M.; Rajabi, Z.; Foroushani, A.R.; Azimi, A.; Fardsanei, F. Phage therapy as an approach to control Salmonella enterica serotype Enteritidis infection in mice. Rev. Soc. Bras. Med. Trop. 2019, 52, 20190290. [CrossRef]

31. Bao, H.; Zhou, Y.; Shahin, K.; Zhang, H.; Cao, F.; Pang, M.; Zhang, X.; Zhu, S.; Olaniran, A.; Schmidt, S.; et al. The complete genome of lytic Salmonella phage vB_SenM-PA13076 and therapeutic potency in the treatment of lethal Salmonella Enteritidis infections in mice. Microbiol. Res. 2020, 237, 126471. [CrossRef] [PubMed]

32. Seo, B.J.; Song, E.T.; Lee, K.; Kim, J.W.; Jeong, C.G.; Moon, S.H.; Son, J.S.; Kang, S.H.; Cho, H.S.; Jung, B.Y.; et al. Evaluation of the broad-spectrum lytic capability of bacteriophage cocktails against various Salmonella serovars and their effects on weaned pigs infected with Salmonella Typhimurium. J. Vet. Med. Sci. 2018, 80, 851-860. [CrossRef] [PubMed]

33. Jamal, M.; Bukhari, S.M.; Andleeb, S.; Ali, M.; Raza, S.; Nawaz, M.A.; Hussain, T.; Rahman, S.U.; Shah, S.S.A. Bacteriophages: An overview of the control strategies against multiple bacterial infections in different fields. J. Basic Microbiol. 2019, 59, 123-133. [CrossRef] [PubMed] 
34. Jurczak-Kurek, A.; Gąsior, T.; Nejman-Faleńczyk, B.; Bloch, S.; Dydecka, A.; Topka, G.; Necel, A.; Jakubowska-Deredas, M.; Narajczyk, M.; Richert, M.; et al. Biodiversity of bacteriophages: Morphological and biological properties of a large group of phages isolated from urban sewage. Sci. Rep. 2016, 6, 34338. [CrossRef] [PubMed]

35. Weber-Dabrowska, B.; Jończyk-Matysiak, E.; Zaczek, M.; Łobocka, M.; Łusiak-Szelachowska, M.; Górski, A. Bacteriophage procurement for therapeutic purposes. Front. Microbiol. 2016, 7, 1177. [CrossRef] [PubMed]

36. Sambrook, J.F.; Russell, D.W. Molecular Cloning: A Laboratory Manual, 3rd ed.; Cold Spring Harbor: New York, NY, USA, 2001; Volume 1.

37. Affolter, M.; Parent-Vaugeois, C.; Anderson, A. Curing and induction of the Fels 1 and Fels 2 prophages in the Ames mutagen tester strains of Salmonella typhimurium. Mutat. Res. 1983, 110, 243-262. [CrossRef]

38. Figueroa-Bossi, N.; Bossi, L. Inducible prophages contribute to Salmonella virulence in mice. Mol. Microbiol. 1999, 33, 167-176. [CrossRef]

39. Garcia-Russell, N.; Elrod, B.; Dominguez, K. Stress-induced prophage DNA replication in Salmonella enterica serovar Typhimurium. Infect. Genet. Evol. 2009, 9, 889-895. [CrossRef]

40. Topka, G.; Bloch, S.; Nejman-Falenczyk, B.; Gąsior, T.; Jurczak-Kurek, A.; Necel, A.; Dydecka, A.; Richert, M.; Węgrzyn, G.; Węgrzyn, A.; et al. Characterization of bacteriophage VB-EcoS-95, isolated from urban sewage and revealing extremely rapid lytic development. Front. Microbiol. 2019, 9, 3326. [CrossRef]

41. Caldeira, C.; Peabody, D.S. Stability and assembly in vitro of bacteriophage PP7 virus-like particles. J. Nanobiotechnol. 2007, 5, 10. [CrossRef]

42. Seemann, T. Prokka: Rapid prokaryotic genome annotation. Bioinformatics 2014, 30, 2068-2069. [CrossRef] [PubMed]

43. Marchler-Bauer, A.; Lu, S.; Anderson, J.B.; Chitsaz, F.; Derbyshire, M.K.; DeWeese-Scott, C.; Fong, J.H.; Geer, L.Y.; Geer, R.C.; Gonzales, N.R.; et al. CDD: A conserved Domain database for the functional annotation of proteins. Nucleic Acids Res. 2011, 39, D225-D229. [CrossRef]

44. Finn, R.D.; Clements, J.; Eddy, S.R. HMMER web server: Interactive sequence similarity searching. Nucleic Acids Res. 2011, 39, W29-W37. [CrossRef] [PubMed]

45. Naville, M.; Ghuillot-Gaudeffroy, A.; Marchais, A.; Gautheret, D. ARNold: A web tool for the prediction of Rho-independent transcription terminators. RNA Biol. 2011, 8, 11-13. [CrossRef] [PubMed]

46. McNair, K.; Bailey, B.A.; Edwards, R.A. PHACTS, a computational approach to classifying the lifestyle of phages. Bioinformatics 2012, 28, 614-618. [CrossRef]

47. Garneau, J.R.; Depardieu, F.; Fortier, L.C.; Bikard, D.; Monot, M. PhageTerm: A tool for fast and accurate determination of phage termini and packaging mechanism using next-generation sequencing data. Sci. Rep. 2017, 7, 8292. [CrossRef]

48. Stothard, P.; Wishart, D.S. Circular genome visualization and exploration using CGView. Bioinformatics 2005, 21, 537-539. [CrossRef]

49. Gautier, N.; Gouy, M.; Gautier, C. SeaView and Phylo_win, two graphic tools for sequence alignment and molecular phylogeny. Comput. Appl. Biosci. 1996, 12, 543-548. [CrossRef]

50. Darling, A.C.E.; Mau, B.; Blattner, F.R.; Perna, N.T. Mauve: Multiple alignment of conserved genomic sequence with rearrangements. Genome Res. 2004, 14, 1394-1403. [CrossRef]

51. Swofford, D.L. Phylogenetic Analysis Using Parsimony (and Other Methods), Version 4; Sinauer Associates: Sunderland, MA, USA, 2003.

52. Yoshida, R.; Nei, M. Efficiencies of the NJp, maximum likelihood, and Bayesian methods of phyogenetic construction for compositional and noncompositional genes. Mol. Biol. Evol. 2016, 33, 1618-1624. [CrossRef]

Publisher's Note: MDPI stays neutral with regard to jurisdictional claims in published maps and institutional affiliations.

(C) 2020 by the authors. Licensee MDPI, Basel, Switzerland. This article is an open access article distributed under the terms and conditions of the Creative Commons Attribution (CC BY) license (http://creativecommons.org/licenses/by/4.0/). 